\title{
WELFARE-BASED \\ MONETARY POLICY \\ RULES IN AN ESTIMATED \\ DSGE MODEL OF THE \\ US ECONOMY
}

by Michel Juillard,

Philippe Karam,

Douglas Laxton

and Paolo Pesenti 
EUROPEAN CENTRAL BANK

\section{WORKING PAPER SERIES}

NO 6 I3 / APRIL 2006

INTERNATIONAL RESEARCH FORUM ON MONETARY POLICY

\section{WELFARE-BASED MONETARY POLICY RULES IN AN ESTIMATED DSGE MODEL OF THE US ECONOMY'}

by Michel Juillard, ${ }^{2}$ Philippe Karam, ${ }^{3}$

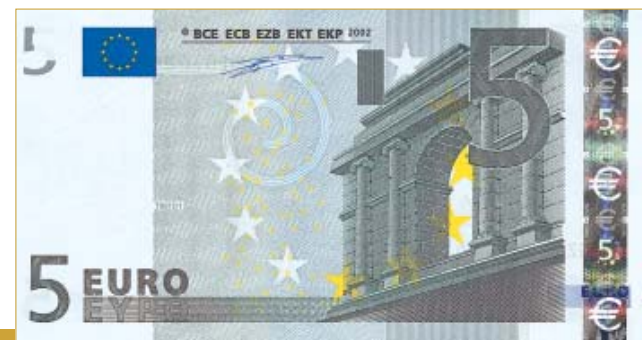

Douglas Laxton ${ }^{4}$ and Paolo Pesenti ${ }^{5}$

In 2006 all ECB publications

will feature

a motif taken

from the

$€ 5$ banknote.
This paper can be downloaded without charge from http://www.ecb.int or from the Social Science Research Network electronic library at http://ssrn.com/abstract_id $=891014$

We thank Ed Nelson, Tom Sargent, Chris Sims, Mike Woodford, and conference participants at the III International Research Forum on Monetary Policy, European Central Bank, May 2005, for comments and suggestions. We also thank Frank Smets and RafWouters, whose work this paper is particularly indebted to, for many useful remarks. The views expressed here are those of the authors, and do not necessarily reflect the position of the International Monetary Fund, the Federal Reserve Bank of New York, the Federal Reserve System, the European Central Bank, or any other institution with which the authors are affiliated.

2 CEPREMAP and University Paris 8, 2 rue de la Liberté, 93526 Saint-Denis Cedex 02, France; e-mail: michel.juillard@ens.fr

3 International Monetary Fund (IMF), 700 19th Street NW,Washington, DC 2043I, United States; e-mail: pkaram@imf. org 4 International Monetary Fund (IMF), Research Department, 700 19th Street NW, Washington, DC 2043I, United States; 


\section{International Research Forum on Monetary Policy: Third Conference}

This paper was presented at the third conference of the International Research Forum on Monetary Policy which took place on May 20-21, 2005 at the ECB. The Forum is sponsored by the European Central Bank, the Board of Governors of the Federal Reserve System, the Center for German and European Studies at Georgetown University and the Center for Financial Studies at Goethe University. Its purpose is to encourage research on monetary policy issues that are relevant from a global perspective. It regularly organises conferences held alternately in the Euro Area and the United States. The conference organisers were Ignazio Angeloni, Matt Canzoneri, Dale Henderson, and Volker Wieland. The conference programme, including papers and discussions, can be found on the ECB's web site (http://www.ecb.int/events/conferences/html/intforum3.en.html)

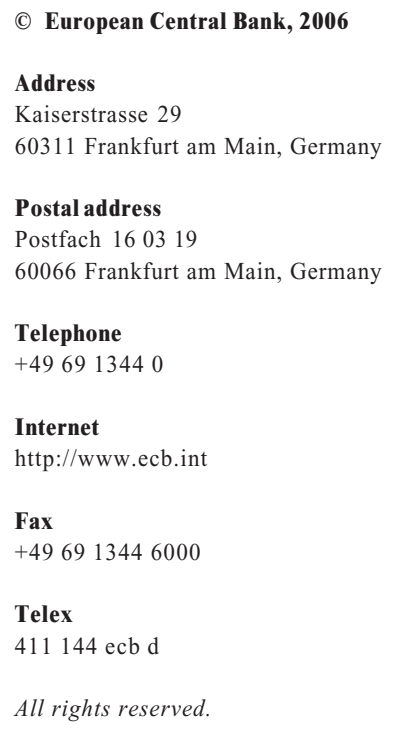

The views expressed in this paper do not necessarily reflect those of the European Central Bank. 


\section{CONTENTS}

Abstract

Non-technical summary

1. Introduction

2. The model

2.1 Households

2.2 Firms

2.3 Government

2.4 Market clearing

3. Taking the model to the data

3.1 Steady-state parameters

3.2 Specification of the stochastic processes

3.3 The data

3.4 Prior distributions and estimation results

3.5 Variance decomposition

3.6 The IRFs for demand shocks

3.7 The IRFs for supply shocks

3.8 Model comparison

4. A simple-welfare-based (SWB) policy rule

4.1 The SWB rule and conventional variability analysis

4.2 What are the welfare consequences of choosing the wrong point on the frontier? 35

4.3 How would these two rules have performed historically?

5. Conclusion

References

Tables

Figures

European Central Bank Working Paper Series 


\begin{abstract}
We develop and estimate a stylized micro-founded model of the US economy. Next we compute the parameters of a simple interest rate policy rule that maximizes the unconditional mean of utility. We show that such a welfare-based rule lies close to the Taylor efficiency frontier. A counterfactual analysis assesses to what extent using such a rule as a guideline for monetary policy would have helped to avoid the inflationary swings of the 1970s and reduce the severity of boom and bust cycles. The paper also provides estimates of the welfare implications of business cycle variability and discusses their relevance.
\end{abstract}

JEL Classification Numbers: C51; E31; E52

Keywords: Competition; Markups; Monetary Policy; Taylor Rule. 


\section{Non-technical summary}

A considerable amount of research over the last decade has attempted to evaluate policy rules in empirically-based macroeconomic models with simple loss functions that penalize output, inflation and interest rate variability. In practice, most of this literature has adopted analytically tractable models to construct Taylor efficiency frontiers, that is, relations between variability in output and variability in inflation, possibly subject to some upward bound on the degree of interest rate variability.

The development of a new generation of optimizing models, as well as methods for evaluating alternative policy rules using explicit welfare criteria, have made it feasible to re-examine the results of this literature from a new perspective. Specifically, we can now use nonlinear models to carry through formal welfare analysis that accounts for the effects that variability has on the mean levels of macro variables, such as labor effort, investment and real income.

This paper develops a stylized micro-founded model of the US economy containing standard features such as habit persistence in consumption, adjustment costs on investment, sticky nominal wages and prices, as well as imperfect competition in both the labor and product markets. Next, we estimate the model in two steps. In the first step, we identify the parameters that influence the long-term relations of the model. These parameters are calibrated on the basis of previous studies, or are computed to fit the observed steady-state levels of real variables. In the second step, we specify prior distributions for the parameters that influence the business cycle and then compute the posterior distributions for each parameter using Bayesian methods. We assess the empirical validity of our model by comparing its fit with the linear model that Smets and Wouters (2004) developed for the US economy, as well as other statistical representations.

We then compute the parameters of a simple interest rate policy rule that maximizes the unconditional mean of utility. We show that such a welfare-based rule lies close to the 
Taylor efficiency frontier. The paper also develops estimates of the welfare implications of excessive variability in the business cycle and shows that for the United States they are small, but significant enough to matter.

Our final exercise is to show what history might have looked like had this rule been used as a guideline for monetary policy. Would it have completely avoided the inflation episode of the 1970s? Would it have significantly modified the macroeconomic performance of the last 20 years? To obtain a glimpse at the answers to these questions, we re-estimate the linearized version of the model starting with data from the early $1950 \mathrm{~s}$ in order to extract historical measures of the relevant shocks. We show that such a rule lies close to the Taylor efficiency frontier and that using such a rule in practice as a guideline for monetary policy would have avoided the double-digit rates of inflation of the 1970s and somewhat reduced the severity of boom and bust cycles. 


\section{Introduction}

A considerable amount of research over the last decade has attempted to evaluate policy rules in empirically-based macroeconomic models with simple quadratic loss functions that penalize output, inflation and interest rate variability — for a survey see Williams (2003). In practice, most of this literature has adopted linear or linearized empirically-based models to construct Taylor efficiency frontiers, that is, plots of the minimum trade-off between variability in output and inflation, possibly subject to some upward bound on the degree of interest rate variability. ${ }^{1}$ Underlying this research agenda have been two implicit assumptions. First, minimizing variability in inflation and detrended measures of output has (somewhat arbitrarily) been regarded as equivalent to maximizing welfare. Second, by focusing on the properties of linearized models, previous research has implicitly overlooked the possibility that the monetary policy process — as described by the reaction function parameters may have significant first-order effects on welfare through its impact on the average level of real variables such as investment, labor effort and real income - see Svensson (2003a,b).

The development of a new generation of choice-theoretic models, as well as methods for evaluating alternative policy rules using explicit welfare criteria, have made it feasible to re-examine the results of this literature from a new perspective. This paper develops a stylized micro-founded model of the US economy and then computes the parameters of a simple interest rate policy rule that maximizes the unconditional mean of utility. We show that such a welfare-based rule lies close to the Taylor efficiency frontier. In a counterfactual analysis we assess to what extent using such a rule as a guideline for monetary policy in practice would have avoided the inflationary swings of the 1970s and reduced the severity of boom and bust cycles.

The paper is organized as follows. Section 2 develops a closed-economy dynamic stochas-

\footnotetext{
${ }^{1}$ Some recent exceptions with formal welfare analysis using perturbation methods include Bergin and Tchakarov (2003), Elekdag and Tchakarov (2004), Kim and Kim (2003), Kollmann (2002), and Straub and Tchakarov (2004).
} 
tic general equilibrium (DSGE) model of the US economy. The model contains a number of features that have become standard in the literature such as habit persistence in consumption, ${ }^{2}$ adjustment costs on investment, nominal rigidities on wages and prices, as well as imperfect competition in both the labor and product markets - see e.g. Christiano, Eichenbaum and Evans (2003), Woodford (2003), Smets and Wouters (2004) and Laxton and Pesenti (2003). Section 3 takes the model to the data. We estimate the model with Bayesian methods and then compare the fit of our model with the linear DSGE model that Smets and Wouters (2004) developed for the US economy. Section 4 specifies a simple policy rule and then computes its parameters by maximizing the unconditional mean of utility. Our results are then compared with the conventional analysis that is based on constructing Taylor efficiency frontiers. Section 5 provides conclusions and suggests a few possible extensions.

\section{The model}

The economy consists of households, firms, and a government. Households are defined over a continuum of unit mass and indexed by $j \in[0,1]$. Each household supplies a differentiated labor input under conditions of monopolistic competition. Firms are also defined over a continuum of unit mass and indexed by $h \in[0,1]$. Each firm produces a specific variety (brand) under conditions of monopolistic competition. ${ }^{3}$

\footnotetext{
${ }^{2}$ We also allow for habit persistence in leisure. Our priors build on results reported in Bayoumi, Laxton and Pesenti (2004), according to which a sufficiently high degree of habit persistence in leisure can induce realistic dynamics of labor effort in response to temporary monetary policy shocks.

${ }^{3} \mathrm{~A}$ multi-country extension of the model introduced in this section is provided by the International Monetary Fund's Global Economy Model (GEM). For a detailed presentation of GEM see Laxton and Pesenti (2003) and Pesenti (2005).
} 


\subsection{Households}

Households' preferences are additively separable in consumption $C$ and labor effort $\ell$. Denoting with $\mathcal{W}_{t}(j)$ the lifetime expected utility of agent $j$ at time (quarter) $t$, we have:

$$
\mathcal{W}_{t}(j) \equiv \mathrm{E}_{t} \sum_{\tau=t}^{\infty} \beta^{\tau-t}\left[U_{\tau}\left(C_{\tau}(j)\right)-V_{\tau}\left(\ell_{\tau}(j)\right)\right]
$$

where $\beta$ is the discount rate. There is habit persistence in consumption according to the specification:

$$
U_{t}(j)=Z_{U, t} \frac{\left(1-b_{C}\right)^{\sigma}\left(C_{t}(j)-b_{C} C_{t-1}\right)^{1-\sigma}-1}{1-\sigma}
$$

where $C_{t-1}$ is past per-capita consumption ${ }^{4}$ and $0 \leq b_{C}<1$. The term $Z_{U}$ is a preference shifter common to all households. The instantaneous felicity (2) is specified such that in a symmetric steady state with $C_{t}(j)=C_{t-1}$ the marginal utility of consumption is independent of the habit persistence parameter $b_{C}$. Similarly, the parametric specification of $V$ is:

$$
V_{t}(j)=Z_{V, t} \frac{\left(1-b_{\ell}\right)^{-\zeta}\left(\ell_{t}(j)-b_{\ell} \ell_{t-1}\right)^{1+\zeta}}{1+\zeta}
$$

where $Z_{V}$ is a shock to labor disutility, $\zeta$ is the inverse of the Frisch elasticity of labor supply and $0 \leq b_{\ell}<1 .^{5}$

Households consume a CES basket of all varieties produced by the firms. Defining as $C(h, j)$ the consumption by household $j$ of the variety $h$, we have:

$$
C_{t}(j)=\left(\int_{0}^{1} C_{t}(h, j)^{1-\frac{1}{\theta_{t}}} d h\right)^{\frac{\theta_{t}}{\theta_{t}-1}}
$$

where $\theta_{t}>1$ is the (possibly time-varying) elasticity of substitution across differentiated goods. Denoting with $p(h)$ the price of variety $h$, standard optimization conditions yield

\footnotetext{
${ }^{4}$ The convention throughout the model is that variables which are not explicitly indexed (to firms or households) are expressed in per-capita (average) terms. For instance, $C_{t} \equiv \int_{0}^{1} C_{t}(j) d j$.

${ }^{5}$ By encompassing habit persistence in leisure, our specification allows for the possibility that business cycles fluctuations may be socially costly to the extent that they result in considerable variability of labor effort.
} 
household $j$ 's demand for $h$ :

$$
C_{t}(h, j)=\left(\frac{p_{t}(h)}{P_{t}}\right)^{-\theta_{t}} C_{t}(j)
$$

where $P$ is the utility-based consumption price index:

$$
P_{t}=\left[\int_{0}^{1} p_{t}(h)^{1-\theta_{t}} d h\right]^{\frac{1}{1-\theta_{t}}}
$$

The individual flow budget constraint for agent $j$ is:

$$
\begin{aligned}
& B_{t}(j) \leq\left(1+i_{t-1}\right) B_{t-1}(j)-P_{t} C_{t}(j)-P_{t} I_{t}(j) \\
& +R_{t} K_{t}(j)+W_{t}(j) \ell_{t}(j)\left[1-\Gamma_{W, t}(j)\right]+\Phi_{t}(j)-T T_{t}(j)
\end{aligned}
$$

Households hold a nominal bond, $B$. The short-term nominal rate $i_{t-1}$ is paid at the beginning of period $t$ and is known at time $t-1$. The short-term rate is directly controlled by the government.

Households accumulate physical capital which they rent to firms at the nominal rate $R$. Investment is measured in terms of consumption baskets. The law of motion of capital is:

$$
K_{t+1}(j)=(1-\delta) K_{t}(j)+\Psi_{t}(j) K_{t}(j) \quad 0<\delta \leq 1
$$

where $\delta$ is the depreciation rate. To simulate realistic investment flows, capital accumulation $\Psi(j) K(j)$ is subject to adjustment costs that are a function of the ratio of investment to capital, $I / K$. The specific functional form we adopt is quadratic and encompasses inertias in investment:

$$
\Psi_{t}(j) \equiv \frac{I_{t}(j)}{K_{t}(j)}\left(1+Z_{I, t}\right)-\frac{\phi_{I 1}}{2}\left(\frac{I_{t}(j)}{K_{t}(j)}-\delta\right)^{2}-\frac{\phi_{I 2}}{2}\left(\frac{I_{t}(j)}{K_{t}(j)}-\frac{I_{t-1}}{K_{t-1}}\right)^{2}
$$

where $\phi_{I 1}, \phi_{I 2} \geq 0$ and $Z_{I}$ is a temporary investment shock. Defining as $I(h, j)$ the demand by household $j$ of the variety $h$ for investment purposes, we have:

$$
I_{t}(h, j)=\left(\frac{p_{t}(h)}{P_{t}}\right)^{-\theta_{t}} I_{t}(j)
$$

As household $j$ is the monopolistic supplier of labor input $j$, it sets the nominal wage for its type of labor, $W(j)$, facing the following downward-sloping demand with (time-varying) 
elasticity $\psi_{t}$ :

$$
\ell_{t}(j)=\left(\frac{W_{t}(j)}{W_{t}}\right)^{-\psi_{t}} \ell_{t}
$$

As shown below, the previous expression reflects firms' cost minimization. Household $j$ takes the average wage prevailing in the labor market, $W$, and the size of overall labor demand, $\ell$, as given processes independent of its own decision. There is sluggish wage adjustment due to resource costs that are measured in terms of the total wage bill. The adjustment cost is denoted $\Gamma_{W}$ :

$$
\Gamma_{W, t}(j) \equiv 1000 \frac{\phi_{W}}{2}\left(\frac{W_{t}(j) / W_{t-1}(j)}{W_{t-1} / W_{t-2}}-1\right)^{2}
$$

where $\phi_{W} \geq 0$. Wage adjustment costs are related to changes in wage inflation relative to the past observed rate for the whole economy, allowing the model to reproduce realistic short-term wage inflation dynamics encompassing nominal inertias.

Agents own the portfolio of all firms. The variable $\Phi$ (in (7) above) includes all profits accruing to households, plus all revenue from nominal adjustment rebated in a lump-sum way to all households. Finally, households pay lump-sum (non-distortionary) net taxes $T T_{t}(j)$ to the government.

Household $j$ chooses bond holdings, capital and consumption paths, and sets wages to maximize its expected lifetime utility (1) subject to (7) and (8). Denoting the stochastic discount rate as $D_{t, \tau}$, or:

$$
D_{t, \tau}(j) \equiv \beta^{\tau-t} \frac{P_{t} U_{\tau}^{\prime}\left(C_{\tau}(j)\right)}{P_{\tau} U_{t}^{\prime}\left(C_{t}(j)\right)}
$$

the first-order conditions with respect to $C_{t}(j)$ and $B_{t}(j)$ yield the Euler equation:

$$
1=\left(1+i_{t}\right) \mathrm{E}_{t} D_{t, t+1}(j)
$$

The first-order conditions with respect to capital $K_{t+1}(j)$ and investment $I_{t}(j)$ yield the familiar Tobin-Q expression:

$$
\frac{1}{\Psi_{t}^{\prime}(j)}=\mathrm{E}_{t}\left\{D_{t, t+1}(j) \pi_{t+1}\left(\frac{R_{t+1}}{P_{t+1}}+\frac{1}{\Psi_{t+1}^{\prime}(j)}\left[1-\delta+\Psi_{t+1}(j)\left(1-\frac{\Psi_{t+1}^{\prime}(j)}{\Psi_{t+1}(j)} \frac{I_{t+1}(j)}{K_{t+1}(j)}\right)\right]\right)\right\}
$$


where $\pi$ denotes the gross inflation rate:

$$
\pi_{t+1} \equiv \frac{P_{t+1}}{P_{t}}
$$

Note that in a non-stochastic steady state $1+R / P$ is equal to the sum of the rate of time preference $1 / \beta$ and the rate of capital depreciation $\delta$.

Finally, the first order condition with respect to $W_{t}(j)$ characterizes the dynamics of real wages:

$$
\begin{aligned}
& \psi_{t} \frac{V_{t}^{\prime}(j)}{U_{t}^{\prime}(j)} \frac{P_{t}}{W_{t}(j)}=\left(\psi_{t}-1\right)\left(1-\Gamma_{W, t}(j)\right)+W_{t}(j) \frac{\partial \Gamma_{W, t}(j)}{\partial W_{t}(j)} \\
& +\mathrm{E}_{t}\left\{D_{t, t+1}(j) \frac{\ell_{t+1}(j)}{\ell_{t}(j)} W_{t+1}(j) \frac{\partial \Gamma_{W, t+1}(j)}{\partial W_{t}(j)}\right\}
\end{aligned}
$$

In the absence of wage rigidities $\left(\phi_{W}=0\right)$, the real wage $W(j) / P$ is equal to the marginal rate of substitution between consumption and leisure, $V^{\prime}(j) / U^{\prime}(j)$, augmented by the markup $\psi /(\psi-1)$ which reflects monopoly power in the labor market. When $\phi_{W}>0$, changes in the marginal rate of substitution translate only gradually into changes in wages since adjustment is costly both on impact (as captured by the component in square brackets) and in the future (as captured by the component in curly brackets).

Optimization implies that households exhaust their intertemporal budget constraint: the flow budget constraint (7) holds as equality and the transversality condition is satisfied:

$$
\lim _{\tau \rightarrow \infty} \mathrm{E}_{t} D_{t, \tau}\left[\left(1+i_{\tau-1}\right) B_{\tau-1}(j)\right]=0
$$

\section{$2.2 \quad$ Firms}

Firm $h$ 's output, $Q(h)$, is produced with the following CES technology:

$$
Q_{t}(h)=Z_{T, t}\left\{(1-\alpha)^{\frac{1}{\xi}} \ell_{t}^{*}(h)^{1-\frac{1}{\xi}}+\alpha^{\frac{1}{\xi}} K_{t}(h)^{1-\frac{1}{\xi}}\right\}^{\frac{\xi}{\xi-1}}
$$

Firm $h$ uses effective labor $\ell^{*}(h)$ (to be defined below) and capital $K(h)$ with constant elasticity of input substitution $\xi>0$ and capital weight $\alpha \in(0,1)$, while $Z_{T}$ is a scale variable reflecting changes in total factor productivity. 
Effective labor $\ell^{*}(h)$ is the product of two components:

$$
\ell_{t}^{*}(h)=\ell_{t}(h)\left(1-\Gamma\left[\ell_{t}(h)\right]\right)
$$

In the expression above, $\ell(h)$ is a CES combination of differentiated labor inputs, supplied by the households:

$$
\ell_{t}(h)=\left[\int_{0}^{1} \ell_{t}(h, j)^{1-\frac{1}{\psi_{t}}} d j\right]^{\frac{\psi_{t}}{\psi_{t}-1}}
$$

where $\ell(h, j)$ is demand of type- $j$ labor input by the producer of good $h$ and $\psi$ is the elasticity of substitution among labor inputs introduced in (11). We assume that changes in labor are subject to firm-specific adjustment costs. These costs are specified relative to the past observed level of labor effort in the economy and are zero in steady state. Specifically, $\Gamma[\ell(h)]$ denotes:

$$
\Gamma\left[\ell_{t}(h)\right]=\frac{\phi_{L}}{2}\left(\frac{\ell_{t}(h)}{\ell_{t-1}}-1\right)^{2}
$$

Firms take the prices of labor inputs and capital as given. Cost minimization implies that the demand for labor input $j$ by firm $h$ is a function of the relative wage:

$$
\ell_{t}(h, j)=\left(\frac{W_{t}(j)}{W_{t}}\right)^{-\psi_{t}} \ell_{t}(h)
$$

where $W(j)$ is the nominal wage paid to labor input $j$ and the wage index $W$ is defined as:

$$
W_{t}=\left[\int_{0}^{1} W_{t}(j)^{1-\psi_{t}} d j\right]^{\frac{1}{1-\psi_{t}}}
$$

Denoting by $R$ the Home nominal rental price of capital, cost minimization yields:

$$
\begin{aligned}
\ell_{t}^{*}(h) & =(1-\alpha)\left(\frac{1}{1-\Gamma_{t}(h)-\ell_{t}(h) \Gamma_{t}^{\prime}(h)} \frac{W_{t}}{M C_{t}(h)}\right)^{-\xi} \frac{Q_{t}(h)}{Z_{T, t}} \\
K_{t}(h) & =\alpha\left(\frac{R_{t}}{M C_{t}(h)}\right)^{-\xi} \frac{Q_{t}(h)}{Z_{T, t}}
\end{aligned}
$$

where the marginal cost $M C(h)$ is given by:

$$
M C_{t}(h)=\frac{1}{Z_{T, t}}\left((1-\alpha)\left(\frac{W_{t}}{1-\Gamma_{t}(h)-\ell_{t}(h) \Gamma_{t}^{\prime}(h)}\right)^{1-\xi}+\alpha R_{t}^{1-\xi}\right)^{\frac{1}{1-\xi}}
$$


The adjustment terms in the previous equations reflects the fact that it takes time for labor inputs to be fully productive in production, so that from the viewpoint of national producers their effective costs are higher in the short term than in steady state.

Consider now profit maximization. Each firm $h$ sets the nominal price $p(h)$ by maximizing the present discounted value of its real profits, taking into account the demand for its product. There are three sources of demand for variety $h$ : it can be consumed by households, it can be used for investment purposes, and it can be consumed by the government. Under the assumption that government spending $G$ falls on the same consumption baskets as private consumption and investment, and aggregating (5) and (10) across households, $Q^{D}(h)$ is total demand for variety $h$ :

$$
Q^{D}(h)=\left(\frac{p_{t}(h)}{P_{t}}\right)^{-\theta_{t}}\left(C_{t}+I_{t}+G_{t}\right)
$$

Similar to (12), there is sluggish price adjustment due to resource costs $\Gamma_{P Q, t}(h)$ measured in terms of total profits. ${ }^{6}$

$$
\Gamma_{P Q, t}(h) \equiv 1000 \frac{\phi_{Q}}{2}\left(\frac{p_{t}(h) / p_{t-1}(h)}{P_{t-1} / P_{t-2}}-1\right)^{2}
$$

where $\phi_{Q} \geq 0$ and $P$ is the price of one unit of $Q$. The quadratic costs of price adjustment are related to changes in firm $h$ 's price inflation relative to the past observed inflation rate.

Firm $h$ sets its prices by maximizing its real profits:

$$
\max _{p_{t}(h)} \mathrm{E}_{t} \sum_{\tau=t}^{\infty} D_{t, \tau}\left(p_{\tau}(h)-M C_{\tau}(h)\right)\left(\frac{p_{\tau}(h)}{P_{\tau}}\right)^{-\theta_{\tau}}\left(C_{\tau}+I_{\tau}+G_{\tau}\right)\left(1-\Gamma_{P Q, \tau}(h)\right)
$$

where $D_{t, \tau}$ is the discount rate of the representative household (shareholder) as defined in (13) above. The first-order condition with respect to $p_{t}(h)$ can be written as:

$$
\begin{aligned}
& \left(1-\Gamma_{P Q, t}(h)\right)\left(p_{t}(h)\left(1-\theta_{t}\right)+\theta_{t} M C_{t}(h)\right)=\left(p_{t}(h)-M C_{t}(h)\right) \frac{\partial \Gamma_{P Q, t}(h)}{\partial p_{t}(h)} p_{t}(h) \\
& +\mathrm{E}_{t}\left\{D_{t, t+1}\left(p_{t+1}(h)-M C_{t+1}(h)\right)\left(\frac{C_{t+1}+I_{t+1}+G_{t+1}}{C_{t}+I_{t}+G_{t}}\right) \frac{\partial \Gamma_{P Q, t+1}(h)}{\partial p_{t}(h)} p_{t}(h)\right\}
\end{aligned}
$$

\footnotetext{
${ }^{6}$ See among others Rotemberg (1982) and Ireland (2001).
} 
The previous expression is the analog of the wage process (17) above. When prices are fully flexible $\left(\phi_{Q}=0\right)$, the equation collapses to the standard markup rule: $p(h)=$ $(\theta /(\theta-1)) M C(h)$ where the fixed gross markup is a negative function of the elasticity of substitution across varieties. When $\phi_{Q}>0$, changes in marginal costs translate only gradually into changes in prices.

\subsection{Government}

Public expenditure $G$ is subject to random shocks. The government finances public spending with lump-sum net taxes:

$$
P_{t} G_{t} \leq \int_{0}^{1} T T_{t}(j) d j
$$

The government controls the short-term rate $i_{t}$. Monetary policy is specified in terms of an annualized interest rate rule of the form:

$$
\begin{aligned}
& \left(1+i_{t}\right)^{4}=\omega_{i}\left(1+i_{t-1}\right)^{4}+\left(1-\omega_{i}\right)\left(1+i_{t}^{+}\right)^{4}+\omega_{1} \mathrm{E}_{t}\left[\frac{P_{t+1}}{P_{t-3}}-\Pi_{t}\right] \\
& +\omega_{2} \mathrm{E}_{t}\left(\log \frac{Q_{t+1}}{Q_{S S}}-\log \frac{Q_{t-3}}{Q_{S S}}\right)+\omega_{3}\left(\log \frac{Q_{t-1}}{Q_{S S}}\right)+Z_{i, t}
\end{aligned}
$$

In the expression above the left hand side is the annualized interest rate, $i_{t-1}$ is the lagged interest rate (with $0<\omega_{i}<1$ ), $i_{t}^{+}$is the 'neutral' interest rate, defined as:

$$
\left(1+i_{t}^{+}\right)^{4}=\frac{\Pi_{t}}{\beta^{4}}
$$

$Z_{i, t}$ is an exogenous nominal shock, $P_{t} / P_{t-4}$ is the year-on-year gross CPI inflation rate, and $\Pi_{t}$ is the (possibly time-varying) year-on-year gross inflation target. The term $\log Q_{t} / Q_{S S}$ is a measure of output gap, where $Q_{t}$ is current aggregate production of the final good and $Q_{S S}$ its steady-state level. 


\subsection{Market clearing}

The model is closed by imposing the following resource constraints and market clearing conditions:

$$
\begin{aligned}
& \ell_{t}(j) \geq \int_{0}^{1} \ell_{t}(h, j) d h \\
& Q_{t}(h) \geq \int_{0}^{1} C_{t}(h, j) d j+\int_{0}^{1} I_{t}(h, j) d j+G_{t}(h)=Q_{t}^{D}(h) \\
& \int_{0}^{1} K_{t}(j) d j \geq \int_{0}^{1} K_{t}(h) d h
\end{aligned}
$$

All profits and adjustment revenue accrue to households:

$$
\int_{0}^{1} \Phi_{t}(j) d j=\int_{0}^{1} \Gamma_{W, t}(j) w_{t}(j) d j+\int_{0}^{1}\left[p_{t}(h)-m c_{t}(h)\right] Q_{t}^{D}(h) d h
$$

Finally, market clearing in the asset market requires:

$$
\int_{0}^{1} B_{t}(j) d j=0
$$

Aggregating the budget constraints across private and public agents we derive the macroeconomic variables used in the simulation exercises.

\section{Taking the model to the data}

The parameterization of DSGE models has been greatly advanced by the development of Bayesian estimation methods. The estimation process described in what follows involves two steps. In the first step, we identify the parameters that influence the deterministic steady state of the model. These parameters are calibrated on the basis of previous studies, or are computed to fit the observed steady-state levels of real variables. In the second step, we specify prior distributions for the parameters that influence the business cycle and then compute the posterior distributions for each parameter using the MetropolisHastings algorithm. To facilitate the comparison with previous results in the literature, when appropriate we discuss the possible sources of difference between our results and the 
ones reported by Smets and Wouters (2004) in their Bayesian DSGE model of the US economy.

\subsection{Steady-state parameters}

The list of the base-case parameters include the rate of time preference, the depreciation rate on capital, the elasticity of substitution between capital and labor, the intertemporal elasticity of substitution, the elasticity of labor supply, the wage and price markups and a scale parameter that determines capital's share in the economy - see Table 1. The quarterly discount rate $\beta$ pins down the equilibrium real interest rate in the model, which we set at $1.04^{-0.25}$ to generate an equilibrium annual real interest rate of 4.0 percent. The quarterly depreciation rate on capital $\delta$ is assumed to be 0.025 , implying an annual depreciation rate of 10 percent. The elasticity of substitution between capital and labour is 0.99 , to be consistent with the Cobb-Douglas specification in Smets and Wouters (2004). ${ }^{7}$ The intertemporal elasticity of substitution $1 / \sigma$ is set equal to 0.8 , an estimate consistent with most empirical studies albeit significantly lower than the one used in models that de-emphasize the role of habit persistence in consumption. ${ }^{8}$

The inverse of the parameter $\zeta$ represents the Frisch elasticity of labor supply which is set to $1 / 3(\zeta=3)$ in the base-case version of the model. ${ }^{9}$ Following Bayoumi, Laxton and Pesenti (2004), the average wage and price markups are set at 16 percent and 23 percent,

\footnotetext{
${ }^{7}$ Erceg, Guerrieri and Gust (2003) suggest however that this parameter should be significantly below one.
} We are in the process of investigating the effects of lower estimates on the fit of the model.

${ }^{8}$ Bayoumi, Laxton, and Pesenti (2004) show that high values of this elasticity along with high rates of habit persistence in consumption significantly help the model to match the hump-shaped responses of consumption found in standard central-bank policy models of the monetary transmission mechanism. However, the empirical fit of our model deteroriates significantly when we use high values for the intertemporal elalsticity. Thus, our model still generates hump-shaped responses, but the lags are shorter than what is typically found in central bank monetary models.

${ }^{9}$ This estimate is at the high end of the range of estimates from micro studies, which vary from about .05 to .35 , but is significantly lower than what is typically used in the real business cycle literature (see e.g. Cooley and Prescott (1995)). 
respectively. These imply steady-state elasticities of substitution among labor inputs $\left(\psi_{S S}\right)$ and differentiated goods $\left(\theta_{S S}\right)$ of 7.25 and 5.35 , respectively. These estimates are consistent with empirical evidence on the magnitudes of markups in the US economy, but alternative views about these key assumptions may be worth exploring both to understand their policy implications and to check their impact on the fit of the model. The steady-state effects on consumption, output, investment and labor effort stemming from imperfect competition in both the product and labor markets are reported in Table 2. Note that in our framework the order of magnitude of the output deviation from the first-best competitive benchmark is as high as 20 percent. ${ }^{10}$

The following steady-state ratios are calibrated to be consistent with Smets and Wouters (2004). The steady-state investment-to-GDP $(I / Q)$ and government-to-GDP $(G / Q)$ ratios are calibrated to be equal to 0.17 and 0.18 , resulting in a consumption-to-GDP ratio of 0.65 . The scale parameter $\alpha$ in the production function (19) is set to generate a value for capital's share of income equal to 0.42 . These assumptions together imply an annual capital-to-GDP ratio of 1.7 .

\subsection{Specification of the stochastic processes}

Our model allows for eight structural shocks, four of which we classify as supply shocks and the other four as demand shocks. ${ }^{11}$ The classification of shocks into demand and supply depends on the short-run covariance between inflation and real GDP. Shocks where real GDP and inflation co-vary positively are classified as demand shocks while shocks that result in

\footnotetext{
${ }^{10}$ The effects reported in Table 2 are closely related to the estimates by Bayoumi, Laxton and Pesenti (2004) in a two-country model. They are also roughly of the same order of magnitude as was reported by Coenen (2003) using the model developed by Smets and Wouters.

${ }^{11}$ In their model of the US economy, Smets and Wouters (2004) allow for ten structural shocks, six of which are specified as first-order stochastic processes and four of which are assumed to be white noise. As in Smets and Wouters (2004), we allow for observation errors to account for any measurement errors in the data and then compare the fit of the model with the observed series to track potential sources of misspecification. While these observations errors are statistically significant, we show that the structural shocks are responsible for explaining most of the variation in the business cycle.
} 
a negative covariance are classified as supply shocks. The stochastic processes for the eight shocks in our model are specified in Table 3. The two elasticities $\theta_{t}$ and $\psi_{t}$ are modeled as noise terms around their steady-state values, while the variables $\left\{G_{t}, Z_{I, t}, Z_{U, t}, Z_{i, t}, Z_{T, t}, Z_{V, t}\right\}$ are assumed to follow first-order stochastic processes. ${ }^{12}$

\subsection{The data}

The list of observable variables we adopt includes real GDP, consumption, investment, real wage, labor hours, the Fed funds rate and the inflation rate (implicit GDP deflator). ${ }^{13}$ This is the same list of seven variables as in Smets and Wouters (2004). However, there are several differences between our approach and theirs.

Smets and Wouters (2004) use data that extend back to the 1950s while we use 1983:Q1 as the beginning of the estimation sample for the base-case version of our model. Because they estimate their model over periods characterized by large swings in inflation, they allow for a unit root in the inflation target $\Pi_{t}$ in the interest rate reaction function to proxy for regime changes in the monetary policy process. By contrast, in estimating the base-case version of our model we focus on the period following the Volcker disinflation of the early 1980s, a period of lower inflation variability. Furthermore, this choice enables us to compare our results with empirical work by Orphanides (2003) who provides detailed documentation of changes in the monetary policy process in the US. ${ }^{14}$

\footnotetext{
${ }^{12}$ Smets and Wouters (2004) also allow for an i.i.d shock that affects the rate of return on capital and a unit-root stochastic process (on an implicit inflation objective) to account for movements between inflation regimes. We use a similar identification scheme as Smets and Wouters (2004) for the other eight random processes, except we allow for serial correlation in the shock that enters the interest rate reaction function while they assume it is white noise - see Table 3 .

${ }^{13}$ The data are all derived from standard sources and are available from the authors. Real GDP, investment, and consumption are published measures taken from the NIPA accounts. Hours worked were taken from the Labor Force Survey.

${ }^{14}$ For sensitivity analysis, we extrapolate the historical stochastic processes over a longer sample period and we estimate the model using data that extend back to the early 1950s. In this particular exercise we adopt the unit-root specification to proxy for shifts in monetary policy regimes.
} 
Smets and Wouters (2004) follow Altig and others (2003) and estimate their real measures of consumption and investment by deflating nominal values by the implicit GDP deflator. This is done to avoid dealing with the positive trend in the investment share of output as a result of the decline in the relative price of investment goods. In the base-case version of our model, we employ the standard real measures of these variables as published in the NIPA accounts, but we are in the process of re-estimating the model with the measures employed in the above studies.

The last difference resides in the way the data are detrended. Smets and Wouters (2004) impose a common time trend in real GDP, consumption, investment, and the real wage, while we use the Hodrick-Prescott filter with a smoothing parameter of 10,000. In addition, we also detrend inflation and the Fed funds rate to eliminate the slight downward trend in nominal interest rates and inflation that occurs over our sample. ${ }^{15}$ Figures 1 and 2 include all trend and detrended measures of our variables. At the end of our sample, our measure of the implicit inflation target is approximately 2.5 percent.

\subsection{Prior distributions and estimation results}

Our assumptions about the prior distributions can be grouped into two categories: (1) parameters for which we have relatively strong priors based on our reading of existing empirical evidence, and (2) parameters where we have fairly diffuse priors. Broadly speaking, parameters in the former group include the core structural parameters that influence, for example, the lags in the monetary transmission mechanism while parameters in the latter category include the parameters that characterize the stochastic processes (i.e., the variances of the shocks and the degree of persistence in the shock processes).

\footnotetext{
${ }^{15}$ The filter that we use to detrend inflation and interest rates is based on the following objective function. Given a sample of 1 to $T$ observations for some series $\left\{y_{t}\right\}$, we compute trend values of the series $\left\{y_{t}^{*}\right\}$ that minimizes $\sum_{t=1}^{T}\left(y_{t}-y_{t}^{*}\right)^{2}+\sum_{t=2}^{T} \Upsilon\left[\left(y_{t}^{*}-y_{t-1}^{*}\right)\right]^{2}$. This is simply a restricted version of the HodrickPrescott filter that penalizes changes in the trend $\left(y_{t}^{*}-y_{t-1}^{*}\right)$ rather than changes in its first difference $\left[\left(y_{t}^{*}-y_{t-1}^{*}\right)-\left(y_{t-1}^{*}-y_{t-2}^{*}\right)\right]$. The trend for the Fed funds rate and inflation has been computed using a value for $\Upsilon$ of 1000 . This produces a smooth value of the inflation target that converges from 4.5 percent at the beginning of our sample to 2.5 percent at the end of our sample.
} 
The first, fourth and fifth columns of Table 4 report our assumptions about the prior distributions for the 11 structural core parameters in the model. This includes the four parameters in the interest rate reaction function $\left[\omega_{i}, \omega_{1}, \omega_{2}, \omega_{3}\right]$, the two habit-persistence parameters $\left[b_{C}, b_{l}\right]$, the two parameters that determine the extent of nominal inertia in wages and prices $\left[\phi_{W}, \phi_{Q}\right]$, the adjustment cost parameters on investment $\left[\phi_{I_{1}}, \phi_{I_{2}}\right]$, and the adjustment cost parameter associated with labor changes $\left[\phi_{L}\right]$. The next to last column reports the type of distribution we assume (Beta, Normal, Gamma, Inverted Gamma). The first column of each table reports our prior about the mean of each parameter and the value in the last column represents a measure of uncertainty in our prior belief about the mean (measured as a standard error). The second and third columns report the posterior means of the parameters, and the $90 \%$ confidence intervals that are based on 100,000 replications of the Metropolis-Hastings algorithm. ${ }^{16}$ The assumptions about the remaining parameters are reported in a similar format in Tables 5 and 6 .

\subsubsection{Reaction function parameters $\left[\omega_{i}, \omega_{1}, \omega_{2}, \omega_{3}\right]$}

Our prior beliefs about the reaction function parameters have been influenced by the empirical work by Orphanides (2003). Using data from the Federal Reserve's Greenbook forecasts (and the Survey of Professional Forecasters for more recent years, post 1997) of inflation and the output gap, Orphanides estimates the following reaction function over the sample

\footnotetext{
${ }^{16}$ The model is estimated in two steps in DYNARE-MATLAB. In the first step, we compute the posterior mode using an optimization routine (CSMINWEL) developed by Chris Sims. Using the mode as a starting point, we then use the Metropolis-Hasting $(\mathrm{MH})$ algorithm to construct the posterior distributions of the model and the marginal likelihood. For one estimation run the whole process takes anywhere from 10-12 hours to complete using a Pentium 4 processor $(3.0 \mathrm{GHz})$ on a personal computer with $1 \mathrm{~GB}$ of RAM. DYNARE includes a number of debugging features to determine if the optimization routines have truly found the optimum and if enough draws have been executed for the posterior distributions to be accurate.
} 
$1982: 3-2002: 4 .^{17}$

$$
\begin{aligned}
& \left(1+i_{t}\right)^{4}=0.81\left(1+i_{t-1}\right)^{4}+0.52 \mathrm{E}_{t} \frac{P_{t+3}}{P_{t-1}} \\
& +0.51 \mathrm{E}_{t}\left(\log \frac{Q_{t+3}}{Q_{S S}}-\log \frac{Q_{t-1}}{Q_{S S}}\right)+0.10\left(\log \frac{Q_{t-1}}{Q_{S S}}\right)+Z_{i, t}
\end{aligned}
$$

The key finding emphasized by Orphanides is that the coefficient on the lagged output gap $\left(Q_{t-1} / Q_{S S}\right)$ is estimated to be small, both in absolute terms and relative to the coefficient on the inflation term $\left(P_{t+3} / P_{t-1}\right)$ and the expected year-on-year change in the output gap three quarters ahead. Orphanides argues that this represents an important change in US monetary policy that could account for better macroeconomic performance over this period relative to earlier periods. Indeed, Orphanides estimates the same regression above over the sample period 1969:1-1979:2 and reports the following equation:

$$
\begin{aligned}
& \left(1+i_{t}\right)^{4}=0.75\left(1+i_{t-1}\right)^{4}+0.44 \mathrm{E}_{t} \frac{P_{t+3}}{P_{t-1}} \\
& +0.14 \mathrm{E}_{t}\left(\log \frac{Q_{t+3}}{Q_{S S}}-\log \frac{Q_{t-1}}{Q_{S S}}\right)+0.19\left(\log \frac{Q_{t-1}}{Q_{S S}}\right)+Z_{i, t}
\end{aligned}
$$

Prima facie, the differences between these two equations may seem subtle. But Orphanides (2003) demonstrates that even coefficients as small as 0.2 on the level of the output gap can result in significant policy errors when there are large and serially correlated errors in estimating the level of the output gap and forecasting future inflation. ${ }^{18}$

\footnotetext{
${ }^{17}$ The reaction function estimated by Orphanides is slightly different than the one we estimate in the base-case version of our model. First, the Orphanides reaction function assumes a fixed constant to proxy for a fixed implicit inflation target and equilibrium real interest rate while we allow for some time variation in both over our sample. Second, Orphanides includes a 3-quarter-ahead measure of the year-on-year inflation rate and a 3-quarter-ahead measure of the year-on-year change in the output gap, while in the base-case version of our model we use 1-quarter-ahead measures for these variables, as they appear in (33). The equation below uses our notation but abstracts from the constant term that Orphanides estimates - see Table 1 in Orphanides (2003) for the complete details. As shown below the fit of our model deteriotates significantly when we use an exact formulation of the reaction function as suggested by Orphanides. However, interestingly enough the mean values we obtain for $\left[\omega_{i}, \omega_{1}, \omega_{2}, \omega_{3}\right]$, namely $[0.79,0.57,0.31,0.11]$, are quite close to the estimates reported by Orphanides over a similar sample period.

${ }^{18}$ Indeed, inaccurate estimates of both the level of the output gap as well as future inflation were very much related during the 1970s - see Laxton and Tetlow(1992) for a discussion of the issues that policymakers grappled with, and the lessons that could be learned.
} 
The following priors were chosen to estimate the four parameters $\left[\omega_{i}, \omega_{1}, \omega_{2}, \omega_{3}\right]$ in the reaction function. We assume normal distributions for $\left[\omega_{1}, \omega_{2}, \omega_{3}\right]$, and a beta distribution for $\omega_{i}$ to restrict it between zero and one. For $\omega_{i}$, we use a prior of 0.8 and a standard error of 0.1 . For the weight on the deviation of inflation from the target $\left(\omega_{1}\right)$ we assume a prior of 0.5. These assumptions are very similar to what is estimated by Orphanides over a similar sample period. By contrast, we set equal priors of 0.25 on the one-quarter-ahead yearon-year change in the output gap $\left(\omega_{2}\right)$ and lagged value of the output gap $\left(\omega_{3}\right)$ to check whether the data move these parameter values closer to those suggested by Orphanides. For all of these parameters we assume a standard error of 0.1. As can be seen in Table 4, the data suggest higher values on the coefficient on the inflation gap and the coefficient on the change in the output gap, but a distinctively smaller coefficient on the level of the output gap. These findings, based on a potentially informative data set and estimation methodology, appear to be in line with the results by Orphanides (2003).

\subsubsection{The habit persistence parameters on consumption and labor effort $\left[b_{C}, b_{l}\right]$}

We assume beta density functions for $\left[b_{C}, b_{l}\right]$ as a way of restricting these habit-persistence parameters to fall between zero and one. We use a higher value for the mean prior of $b_{C}$ (0.90) than for $b_{l}(0.75)$ and in both cases we use a standard error of 0.05 . The posterior mean for the habit persistence parameter on consumption is estimated to be 0.83 and the posterior mean for the habit persistence parameter on labor effort is 0.72 . As will be seen later when evaluating the impulse response functions of the model, these results are consistent with conventional views about the monetary transmission mechanism, which suggest that there are significant lags in the monetary transmission mechanism. Values around 0.7 for the habit persistence parameter on labor effort suggest that the US labor market is not characterized by a high degree of hysteresis. 


\subsubsection{Nominal inertia in wages and prices $\left[\phi_{W}, \phi_{Q}\right]$}

We use normal distributions for these parameters and equal prior means of 1.4 with a standard error of 0.1 . The choice of these priors is based on the results by Bayoumi, Laxton and Pesenti (2004), whereby a similar model was calibrated to match the properties of the Federal Reserve Board's FRB-US model of the monetary transmission mechanism. The posterior mean is slightly higher for $\phi_{W}$ (1.41) and slightly lower for $\phi_{Q}$ (1.37). These estimates, combined with the estimates on the wage and price markups reported in Table 1, suggest a sacrifice ratio of slightly under 2 for the US economy. Interestingly, in a sensitivity analysis where we reduce both parameters to 0.7 to see how the fit of the model changes, we find that this results in a sizeable improvement in fit with a sacrifice ratio that is closer to 1.0. This provides some additional evidence that the inflation process has probably become less persistent than in earlier periods - see Erceg and Levin (2001) and Laxton and N'Diaye (2003) for a discussion of these issues. Moreover, this may suggest that models of the US economy estimated over long samples may not control properly for different sources of inflation persistence and ultimately overstate its extent. ${ }^{19}$ In an another sensitivity case where we track the implications of doubling the values of $\phi_{W}$ than $\phi_{Q}$ we find a significant deterioration in the fit of the model. Finally, and as a way to demonstrate the important role that nominal inertias play in fitting the data, we set both $\phi_{W}$ and $\phi_{Q}$ parameters to zero and note a dramatic deterioration in the fit.

\subsubsection{Adjustment costs on investment $\left[\phi_{I_{1}}, \phi_{I_{2}}\right]$ and hours worked $\left[\phi_{L}\right]$}

We choose normal distributions for these parameters. The prior mean on the parameter that determines adjustment costs on changes in the capital stock $\left(\phi_{I_{1}}\right)$ is set at 1.0, a low value relative to the parameter that determines adjustment costs on changes in investment

\footnotetext{
${ }^{19}$ This is another reason why results based on a shorter sample period may be more reliable.
} 
$\left(\phi_{I_{2}}\right)$, which is set at $80.0 .^{20}$ The standard errors are set at 10 percent of the magnitude of the mean prior. Bayoumi, Laxton and Pesenti (2004) show that parameters of this magnitude are needed to generate realistic hump-shaped responses of investment in response to monetary-policy-induced interest rate shocks. The posterior mean is slightly lower for $\phi_{I_{2}}(77.9)$ and slightly higher for $\phi_{I_{1}}(1.01)$, compared to their respective relative priors. As for the parameter on labor adjustment cost, the prior mean for $\phi_{L}$ has been set equal to 0.5 with a standard error 0.1 and the posterior mean is estimated to be slightly higher.

\subsubsection{Stochastic processes}

To specify the parameters that govern the stochastic processes, we follow the same basic approach as Smets and Wouters (2004) - see Tables 5 and 6. For the $\lambda$ parameters that determine the degree of persistence in the shock processes we use beta distributions and set all mean priors to 0.85 and their standard deviations to 0.1 - see Table 5 . For the standard errors of the shock processes we use inverted gamma distributions with diffuse priors. For the shocks that affect investment we set a mean prior equal to 0.05 and for the markups on wages and prices we set a mean prior equal to 1.0, while for all the other shocks the priors for the means are set equal to 0.01 .

The two stochastic processes exhibiting the most persistence are government absorption and productivity (0.95 and 0.89 for posterior means) and the two shocks with the least persistence are the shocks that affect investment and the Fed funds rate (0.69 and 0.79). The posterior mean of persistence in the shocks to the marginal utility of consumption and marginal disutility of labor effort are slightly above their respective prior means of 0.85 . The estimates of the standard errors of the structural shocks are reported in Table 6 . Their

\footnotetext{
${ }^{20}$ In some of the empirical work, it has not been uncommon to ignore adjustment costs associated with changes of the capital stock. For example, Smets and Wouters (2004) and Christiano, Eichenbaum and Evans(2003) assume that there are only adjustment costs on changing investment as these are perceived to be the most critical elements in generating hump-shaped investment responses. We show below that there are mild costs in terms of fit from imposing $\phi_{I_{1}}$ equal to zero.
} 
interpretation may not be straightforward, as it requires a detailed technical knowledge of the model and the scale of the variables. Consequently, it is probably more informative to present the implications of the different shocks simply by looking at how they account for variability in the observable series. For completeness, Table 7 reports the priors and posterior means for the observation errors. These observation errors are relatively small as can be seen by examining the fitted values and the actual series — see Figure 11.

\subsection{Variance decomposition}

Tables 8 and 9 report the contribution of each structural shock to variability in real GDP, year-on-year inflation and the Fed funds rate. Table 8 reports the results for the demand shocks which include shocks to consumption, investment, government absorption and the Fed funds rate. Table 9 reports the results for the supply shocks which include shocks to productivity, labor supply, and the two white noise shocks affecting wage and price markups. In both cases, the row at the bottom of the table provides a measure of the total variance contribution of demand and supply shocks.

A comparison of Tables 8 and 9 show that demand shocks account for more of the variance in the Fed funds rate than supply shocks, while supply shocks account for a larger proportion of the variance in GDP and in year-on-year inflation than demand shocks. Furthermore, Table 8 shows that most of the variation in GDP has been driven by shocks to consumption and investment and very little variation has been driven by shocks to the Fed funds rate or government absorption. These two dominant sources of demand shocks also result in a significant contribution to variability in the Fed funds rate, which should be expected over periods where the US monetary authorities have been successful in actively working against the inflationary implications of such shocks. Table 9 reports that the dominant source of supply shocks for GDP have been labor supply shocks. As for the variability in inflation, the labor supply shock and the price markup shock have provided significant contributions, followed by the productivity shock, with little impact from the wage markup shock. 


\subsection{The IRFs for demand shocks}

Figure 3 reports the impulse responses for a one-standard deviation increase in the Fed funds rate. The Fed funds rate increases by about 40 basis points and as a result output, consumption, investment, hours worked, and the real wage all fall in the short run and display hump-shaped dynamics that troughs after about four quarters. There is a similar small reduction in year-on-year inflation (which lags output) reflecting the significant inertia in the inflation process. Figure 4 reports the results for a shock to government absorption. This shock is expansionary in the short run and induces higher output and work effort. However, to restrain inflationary forces, real interest rates rise and this crowds out consumption and investment. The two remaining demand shocks are the shocks that affect consumption and investment as depicted in Figures 5 and 6 . These shocks are assumed to be positively correlated. For the $Z_{U}$ shock, both consumption and investment rise in the short run and this requires an increase in real interest rates to return inflation back to the assumed inflation target. For the $Z_{I}$ shock, investment rises in the short run and the rise in the real interest rate crowds out consumption sufficiently in the short run to generate the savings necessary to finance the higher level of investment. However, over time the higher level of capital permits a higher level of consumption. Finally, and as can be seen in all of these figures, inflation and output co-vary positively in the short run.

\subsection{The IRFs for supply shocks}

Figure 7 reports the results for a shock that reduces the wage markup and expands labor supply. In this case, the real wage falls and there is an expansion in output, hours worked, consumption and investment. Inflation falls and the Fed funds rate is reduced over time to gradually push inflation back to control. Figure 8 deals with a shock that reduces the price markup. This has very similar short-run qualitative effects to a wage-markup shock, except that the real wage rises in the short run. Figure 9 reports the results for a productivity 
shock. While this results in an increase in output, consumption, investment and the real wage, there is a reduction in hours worked as workers consume more leisure. As pointed out by Gali (1999) and others, this feature severely constrains the potential role of productivity shocks in DSGE models as it implies a strong negative correlation between hours worked and output. Figure 10 reports the results for a negative shock to labor supply. This induces an increase in the real wage and results in a reduction in output, consumption, investment and hours worked. Finally, we note that under all of these four shocks, a negative covariance exists between output and inflation in the short run.

\subsection{Model comparisons}

The estimation strategy employed above involves linearizing the DSGE model and then using Bayesian methods to develop point estimates and confidence intervals for the model's parameters. A natural method to assess the empirical validity of the linearized DSGE model is to compare the fit of the model with other available linear DSGE models, or perhaps an even larger class of non-structural linear reduced-form models such as VARs or BVARs - see Sims (2003) and Schorfheide (2004). For example, Smets and Wouters (2004) compare the marginal likelihood of their estimated DSGE model with VAR models and BVAR models. In their application using US data, they show that if a sufficient number of structural shocks (10 of them) are specified for the DSGE model, the latter compares favorably in terms of fit to both the VAR and BVAR class of models. We conduct a similar model-comparison exercise in this section, but in addition we also compare directly the fit of our model to that of Smets and Wouters (2004). ${ }^{21}$

Table 10 reports the marginal likelihood of eight BVARs (1 to 8 lags) based on Sims and

\footnotetext{
${ }^{21}$ We do not compare the fit of our model with unrestricted VAR models, given their well-known poor out-of-sample forecasting performance relative to the BVAR class of models. We find that a comparison of the fit of one DSGE relative to other DSGE class of models to be a much more interesting exercise than a comparison to non-structural BVAR models, since it provides more useful direct information about how a model can be potentially improved.
} 
Zha (1998) priors and shows that this likelihood criteria deteriorates for BVARs of lag-order 3 and higher. ${ }^{22}$ The ninth row reports the marginal likelihood of the Smets and Wouters (2004) model estimated with our data over the 1983:01-2003:2 sample after we remove the unit root specification for the inflation target. ${ }^{23}$ The tenth row of the table reports the marginal likelihood of the base-case version of our DSGE model. As can be seen in the table, the Smets and Wouters (2004) model fits better than BVAR models of lag-order 1, 6 and higher, but worse than BVARs with 2 to 5 lags. ${ }^{24}$ By contrast, our DSGE model seems to dominate all lag-order BVARs in terms of fit. ${ }^{25}$

\subsubsection{What assumptions help our model fit the data?}

Table 11 reports a set of estimates of the marginal likelihood when we alter the specification of some equations in the model or restrict certain parameter values. The second row in the Table reports the marginal likelihood for the case where we replace the interest rate reaction function in the model with the Orphanides (2003) specification which uses 3-quarter-ahead measures of year-on-year inflation and the change in the output gap rather than the one-

${ }^{22}$ The marginal likelihood values for the BVAR were computed using a program developed by Chris Sims. The BVAR used here combines a specific type of a Minnesota prior with dummy observations. The prior decay and tightness parameters are set at 0.5 and 3 , respectively. As in Smets and Wouters (2004), the parameter determining the weight on own-persitence (sum-of-coefficients on own lags) is set at 0.5 and the parameter determining the degree of co-persitence is set at 5. Smets and Wouters (2004) also report results where priors are constructed from training samples.

${ }^{23}$ Recall that in our case we detrend inflation and the Fed funds rate while Smets and Wouters (2004) allow for a unit root in the inflation process.

${ }^{24}$ Using different data and a different estimation sample, Smets and Wouters (2004) find that their DSGE model fits better than BVARs. Given that BVARs have been designed specifically to fit data it may not be a fair test to compare a tightly-specified DSGE model, which could be used for policy analysis, with a non-structural BVAR that cannot address the most basic policy issues. Still, until DSGE models have been developed to the point where several benchmark models are readily available, BVARs may be a useful standard of comparison. Another important limitation of BVARs is that they, in general, will not nest the underlying reduced-form of the DSGE model.

${ }^{25}$ We are in the process of incorporating some of our specific modeling assumptions into the Smets and Wouters (2004) model to see which assumptions help our model fit better over the last two decades. We are also attempting to see how our model's fit compares to the fit of the Smets and Wouters (2004) model using their longer sample and unit-root assumption for the inflation objective. 
quarter-ahead measures we adopt in our model. The fit of the model deteriorates as the marginal likelihood declines from -596.03 to -605.50 . Orphanides (2003) does not report results with shorter forecast horizons on these two variables and we do not know if his data and estimation methodology would yield similar conclusions. Since forecast uncertainty typically increases with the forecast horizon, one possible interpretation of these results would be that the monetary authorities place greater emphasis on near-term forecasts when setting the Fed funds rate. ${ }^{26}$

Our interest rate reaction function allows for two sources of persistence in the Fed funds rate. It contains a standard interest-rate smoothing term that allows the Fed funds rate to adjust gradually in response to changes in the inflation forecast and the outlook for the real economy. Moreover, it also allows for the possibility that there can be departures from the policy rule (measured as a structural shock term) which can themselves be serially correlated. In order to understand the implications of eliminating the lag in the reaction function we computed the marginal likelihood assuming that $\omega_{i}=0$. However, for the model to continue to satisfy the Blanchard-Kahn conditions we respecified the prior on the inflation term to have a mean of 1.5 and a standard error of 0.1 . This specification looks very similar to the original Taylor rule which did not allow for inertia. The fit of the model deteriorates substantially as the marginal likelihood falls from -596.03 to -610.33 . Woodford (2003a) has shown that inertia in the policy rate will generally be optimal in standard DSGE models. Interestingly, as we discuss below, in our model we find that the optimal degree of inertia is actually greater than what we observe in the data.

The remaining experiments in Table 11 have been discussed above and can be summa-

\footnotetext{
${ }^{26}$ Sims (2002) has evaluated the Fed's Greenbook forecasts, which are derived from judgmental pooling of information from many different sources, and found that over the period 1979-95 their accuracy was significantly better than BVARs. We believe that this would generally be the case for other central banks that invest significant resources in understanding the data and generate near-term forecasts primarily on the basis of judgment. This does not negate the usefulness of using out-of-sample forecasting accuracy as a way to assess alternative models.
} 
rized briefly. The fourth row of the Table shows the implications of eliminating nominal rigidities in the model $\left(\phi_{W}=\phi_{Q}=0\right)$. There is a massive deterioration in fit as the marginal likelihood falls to [-759.05]. Next we report experiments where we double and halve these parameters. When we restrict $\phi_{W}=\phi_{Q}=2.8$ there is significant deterioration in fit as the marginal likelihood falls to -599.65 . However, when we impose lower values such as $\phi_{W}=\phi_{Q}=0.7$, there is a sizeable improvement in fit as the marginal likelihood increases to -595.06 . The second last row shows that restricting the correlation of the shocks that enter the consumption and investment equations to zero results in a significant deterioration of the fit of the model (-601.40). Finally, the last row follows Christiano and others (2001), and Altig and others (2003) and excludes adjustment costs on changing the capital stock $\left(\phi_{I 1}=0\right)$. As shown, under this restriction there is a mild deterioration in fit $(-596.75)$.

\section{A simple-welfare-based (SWB) policy rule}

Most research assessing monetary policy rules over the last decade has been based on linearized versions of models, and policy rules have been evaluated with simple quadratic loss functions that penalize variability in output, inflation and interest rates. The development of perturbation methods has now made it feasible to take second-order approximations of nonlinear models to do formal welfare analysis that accounts for the effects that variability has on the mean levels of macro variables, such as labor effort, investment and real income. This section uses the algorithm developed by Kim, Kim, Schaumburg and Sims (2003) to compute the stochastic steady state of the model under alternative parameterizations of a simple monetary policy rule, where the Fed funds rate is assumed to respond to both onequarter-ahead forecasts of year-on-year inflation and the year-on-year change in the output gap as in (33). The parameters of this rule are then optimized to maximize the unconditional mean of utility. We will refer to this rule as a simple-welfare-based (SWB) policy rule. We then compare the results of this analysis with more conventional analysis, which has been based on constructing Taylor efficiency frontiers. 
As a caveat, in what follows we do not attempt to characterize the optimal statecontingent monetary policy stance tout-court. First, such a rule would only be optimal in the context of the specific model that is being considered and may not be robust to model uncertainty. ${ }^{27}$ Second, and again because robustness is a concern, we want to focus on a rule that embodies some of the insights gleaned from previous work on monetary policy using different types of models. Third, we want the rule to be successful in achieving an inflation rate that is equal, on average, to a prespecified inflation target. ${ }^{28}$ Fourth, we want the rule to be simple enough that it would be possible to implement it as a guideline for monetary policy analysis.

All of these considerations lead us to specify a simple monetary policy rule of the following form:

$$
\left(1+i_{t}\right)^{4}=\left(1+i_{t-1}\right)^{4}+\omega_{1} \mathrm{E}_{t}\left[\frac{P_{t+1}}{P_{t-3}}-\Pi_{t}\right]+\omega_{2} \mathrm{E}_{t} \log \left[\frac{Q_{t+1}}{Q_{t-3}}\right]
$$

which is a modified version of the Orphanides (2003) rule and our estimated rule (33). A few features of this rule are worth highlighting. First, the coefficient on the lagged interest rate has been imposed to be equal to one. This condition ensures that the mean level of inflation is approximately equal to the prespecified target when doing perturbation analysis. Second, the rule is not dependent on any direct measure of the equilibrium real interest rate. ${ }^{29} \mathrm{In}$ addition, because of the problems associated with measuring the equilibrium level of the

\footnotetext{
${ }^{27}$ Demertzis and Tieman (2004) investigate the conditions under which robust rules are preferable to optimal rules when there is model uncertainty. They find that the higher the expected loss from applying robust rules to an incorrectly specified model, and the more risk averse the policymaker, the more the robust rules are preferable to optimal rules.

${ }^{28}$ This is never a concern when working with linearized versions of a model, because the mean level of inflation will be tied down entirely by the inflation target that enters the reaction function. With secondorder approximations, this will only be the case under certain specifications of the policy rule.

${ }^{29}$ While uncertainty in the equilibrium real interest rate is obviously much more of a concern in emerging market economies, it can be argued that significant shifts in the equilibrium rate have occurred in larger and more stable economies like the United States as well.
} 
output gap, the rule does not place any weight on such variable. ${ }^{30}$ However, following Orphanides(2003) we allow for year-on-year changes in the output gap. ${ }^{31}$

One further restriction which has been imposed consistently in studies of this type concerns the degree of interest rate variability. Without any restrictions on interest rate variability, optimal policy rules are typically found to induce variability in the policy rate that is many times greater than what is observed over history - see Williams (2003). To restrict variability in the policy rate we eliminate all values of $\left[\omega_{1}, \omega_{2}\right]$ that would generate a standard deviation in the first-difference of the Fed funds rate above 0.50. This estimate is approximately the degree of variability observed in changes in the Fed funds rate over the last two decades. We will refer to this rule as the SWB1 rule. We also consider an alternative policy rule (SWB2) that allows this measure of variability in the Fed funds rate to rise to 1.0 , an estimate that is more consistent with variability over the last fifty years in the United States.

The $\left[\omega_{1}, \omega_{2}\right]$ weights in the SWB policy rule are varied in increments of 0.05 between 0.05 and 2.0 or 2.5, producing 2000 values for the unconditional mean of utility. The SWB1 rule that produces the largest unconditional mean level of welfare places a weight of 0.25 on the inflation term and a weight of 0.45 on the output-gap growth term. Interestingly, this rule

\footnotetext{
${ }^{30}$ Entering the level of the output gap into a policy rule also causes computational problems because the stochastic equilibrium of the model will be a function of the form of the policy rule itself, thus requiring that the underlying measure of potential output is consistent with the stochastic equilibrium of the model. For example, one method would be to use a model-consistent two-sided filter, or perhaps even the flex-price measure of output to measure potential output — see Woodford (2003b). While this analysis may be interesting for understanding the fundamental role of policy in the model, it raises some difficult practical issues about measuring potential output with real data while also raising questions about the sensitivity of results to model-specific features.

${ }^{31}$ There is a presumption here that it is easier to measure the growth rate of potential output than its level. In the experiments that follow, we have not allowed for uncertainty in the growth rate of potential output, but rather assumed it can be estimated with perfect certainty. This is obviously an extension that would be worth pursuing, recalling that measures of the growth rate of potential output in the past have been marred by large serially correlated errors. However, we doubt that the measurement errors of potential growth in the 1970 s would be repeated, given a more general and greater appreciation of the role that supply shocks play in the economy — see Laxton and Tetlow (1992).
} 
bears some resemblance to nominal-income targeting — see e.g. Rudebusch (2002a), except the weight on detrended output growth is greater than the weight on inflation. Allowing variability in the Fed funds rate to rise from 0.5 to 1.0 produces a more aggressive SWB2 rule with higher weights on inflation and output terms (0.45 and 2.25, respectively).

\subsection{The SWB rule and conventional variability analysis}

To compare these two SWB rules with more conventional analysis (based on arbitrary loss functions penalizing variability in output and inflation), we first plot the standard deviations for both year-on-year inflation and output for the same $\left[\omega_{1}, \omega_{2}\right]$ weights generated above, and under the two constraints imposed on interest rate variability (0.5 and 1.0$)$. We then compare these frontiers to the variability implied by the two SWB rules - see Figure 13. Interestingly, the two SWB rules lie almost directly on these two frontiers. This suggests that the combination of shocks and distortions in the model implies that allowing excessive variability in both inflation and output may have detrimental welfare implications, and that successful policies in reducing variability would be preferred over other policies that were not as successful in avoiding boom and bust cycles.

Table 12 compares the stochastic equilibrium of the DSGE model under the two rules, both in terms of mean deviations from the deterministic steady state and in terms of variability. The second row of the table reports welfare losses measured in terms of consumption equivalents. These are measured as percent deviations relative to a deterministic steady state with perfect competition in both the labor market and product market. For example, under the SWB1 rule welfare is 14.92 percent lower than in an hypothetical world that is not subjected to any sources of variability. An assessment of the welfare implications of the two rules is obtained by computing the difference in welfare in the two cases. From comparing these two estimates it can be seen that welfare is higher by about 0.25 percent under the more aggressive SWB2 rule. As can be seen in Figure 13 and in Table 12, the more aggressive rule is successful in reducing GDP variability by 0.7 percentage points and 
raising real GDP by 0.4 percent, while it raises the variability in inflation by 0.8 percentage points. These estimates are moderate, but significantly larger than the estimates suggested by Lucas (2002). ${ }^{32}$ Moreover, these estimates would obviously become significantly larger if we were to compare the differences between good- and bad-performing rules, rather than two rules that result in reasonably good macroeconomic performance. ${ }^{33}$

\subsection{What are the welfare consequences of choosing the wrong point on the frontier?}

Svensson (2003a) argues that a transparent inflation targeting framework would make explicit the weights in a standard quadratic loss function, but there is no clear guidance about how policymakers would choose such weights in practice. One potential advantage of developing a formal welfare approach to monetary policy is that it could provide some quantitative guidance about what kind of weights on inflation and output would be more consistent with social preferences.

In Figure 13, the implicit weight on variability in inflation is higher than the implicit weight on output when the rule is less aggressive at trying to stabilize the economy, but with a higher implicit weight on variability in output under the more aggressive rule. To understand the welfare implications of choosing the wrong point on the frontier, Figure 14 reports the welfare losses associated with choosing sub-optimal points along the frontier. It is interesting that these differences are very small under the less aggressive rule, but become more significant under the more aggressive SWB2 rule.

For example, under the SWB2 rule the standard deviation of inflation and output are 2.2 and 1.4 percent, respectively. Attempts to reduce inflation below one percentage point would induce variability in the business cycle that could lower welfare by about 0.1 percent.

\footnotetext{
${ }^{32}$ Our results are more in line with Gali, Gertler and Lopez-Salido (2003).

${ }^{33}$ Needless to say, in this case it would be difficult to characterize an interesting and plausible badperforming rule, since such policies would not likely be repeated systematically.
} 
These estimates are relatively small and might be interpreted as providing some support for Svensson's suggestion. However, the welfare-maximizing point on the frontier as well as the position of the frontier will obviously depend on a host of modeling assumptions, that influence the sources of shocks and persistence in the economy. As our understanding of the economy changes over time, so will the position of the frontier and the point that maximizes welfare.

It is interesting that under both cases, the two SWB rules permit higher variability in inflation than what has been practiced by some explicit-inflation targeting central banks, which seem to place a higher weight on inflation variability than output variability. Whether or not this reflects different assumptions about the magnitudes of distortions, sources of shocks and degree of persistence in their economies, or deeper concerns about the credibility of a more flexible inflation-targeting framework remains an open question.

\subsection{How would these two rules have performed historically?}

The previous analysis was based on the asymptotic stochastic properties of the model under two SWB policy rules. Our final exercise is to show what history might have looked like had either rule been used as a guideline for monetary policy. Would it have completely avoided the inflation episode of the 1970s? Would it have significantly modified the macroeconomic performance of the last 20 years?

To obtain a glimpse at the answers to these questions, we re-estimated the linearized version of the model starting with data from the early 1950s in order to extract historical measures of the relevant shocks. In dealing with this longer sample we employed the same method as Smets and Wouters (2004) by allowing for a unit root in the inflation target. ${ }^{34}$ Next, we eliminated the shocks to the inflation target ${ }^{35}$ and the interest rate reaction

\footnotetext{
${ }^{34}$ In this case, we did not use detrended data for the Fed funds rate and inflation, but allowed the Kalman filter to estimate the underlying changes in the inflation objectives that would be consistent with explaining the movements between regimes.

${ }^{35}$ The model was estimated under the working assumption of a fixed inflation target of 2.5 percent.
} 
function to observe how the two IFB rules would have performed if the paths of the other stochastic processes had remained unchanged.

Figure 15 reports the results for inflation and output under the SWB1 rule and Figure 16 reports the results for the more aggressive SWB2 rule. In the top panels of both Figures, we also report plus-and-minus two standard deviations for the theoretical distributions of inflation obtained from Table 12 (2.8 in the SWB1 case and 4.4 in the SWB2 case) centered around the assumed inflation objective of 2.5 percent. As can be seen in the top panels of these figures, both rules would have avoided the double-digit rates of inflation of the 1970s, but the upper band would have been tested twice during the two historical inflation peaks under SWB1 (1974Q3-1975Q1 and 1980Q2-1982Q3) and more frequently under SWB2 (1970Q1-1971Q2, 1980Q4-1983Q2 and 1990Q4-1992Q3). By contrast, the two rules would have been successful delivering stable inflation over the last decade [excepting the early period in the 1990s under SWB2 also high post 2000 under SWB2].

In terms of output variability both rules reduce variability over the entire sample, but the more aggressive SWB2 rule performs significantly better [throughout], in particular during the 1970s. Moreover, over the last two decades, the actual outcomes for output and inflation are much closer in line with the two rules when compared with the 1970s. It is perhaps not surprising that rules optimized for the experiences of the last two decades would not perform as well at controlling inflation over other periods such as the 1970s, but the differences are quite stark. More work needs to be done to understand why this is the case, but our initial preliminary analysis suggests that the nature of the shocks, and not policy errors, were the main culprits. Indeed, in our estimation results over the full sample the magnitude of supply shocks increases significantly relative to what was estimated over the last two decades and reported in Table 9 . 


\section{Conclusion}

Three recent developments have posed the conditions for a new and exciting agenda for macro modeling research. They include (1) the elaboration of theoretical models based on stronger choice-theoretic foundations, (2) a vastly improved empirical methodology that has helped to close the gap between econometric theory and practice, and (3) the diffusion of numerical methods that allow researchers to move beyond linear approximations of their models and conduct formal welfare analysis using higher-order approximations. This paper exploits all three of these developments. We specify a small closed economy model of the United States economy and estimate it with Bayesian methods. We then compute the parameters of a simple policy rule that maximizes the unconditional mean of utility. We show that such a rule lies close to the Taylor efficiency frontier and that using such a rule in practice as a guideline for monetary policy would have avoided the double-digit rates of inflation of the 1970s and reduced the severity of boom and bust cycles. The paper also develops estimates of the welfare implications of excessive variability in the business cycle and shows that for the United States they are small, but significant enough to matter.

A long list of extensions is in the cards, starting with sensitivity analysis on the specification of the reaction function. We are close to implementing a procedure that will allow us to consider less-restrictive reaction functions that can depend on multi-period forecasts of inflation and real variables. We plan to do a more systematic comparison of the properties of our model with Smets and Wouters (2004), to better understand how differences in modeling assumptions, sample periods, and data measurement can explain differences in results. Finally, we plan further sensitivity analysis with the deeper structural parameters that affect the steady state of the model. 


\section{References}

[1] Altig, D., L. Christiano, M. Eichenbaum and J. Linde (2003). "Technology Shocks and Aggregate Fluctuations," Working Paper, Northwestern University.

[2] Anderson, E. W., L. P. Hansen and T. Sargent (2003). "A Quartet of Semigroups for Model Specification, Robustness, Prices of Risk, and Model Detection," Working Paper.

[3] Bayoumi, T., D. Laxton and P. Pesenti (2004). "Benefits and Spillovers of Greater Competition in Europe: A Macroeconomic Assessment." NBER Working Paper No. 10416 (Cambridge, Massachusetts: National Bureau of Economic Research).

[4] Bergin, P. and I. Tchakarov (2003). "Does Exchange Rate Risk Matter for Welfare? A Quantitative Investigation," NBER Working Paper No. 9900 (Cambridge, Massachusetts: National Bureau of Economic Research).

[5] Bryant, R.C., P. Hooper and C.L. Mann (1993). Evaluating Policy Regimes. The Brookings Institution, Washington D.C.

[6] Christiano,L., M. Eichenbaum and C. Evans. (2003). "Nominal Rigidities and the Dynamic Effects of a Shock to Monetary Policy," Journal of Political Economics, forthcoming.

[7] Christiano, L., R. Motto and M. Rostagno (2004). "The Great Depression and the Friedman-Schwartz Hypothesis," Working Paper, Northwestern University.

[8] Coenen, G. (2003). Discussion of "When Leaner Isn't Meaner: Measuring Benefits and Spillovers of Greater Competition in Europe." Presented at the 2nd International Research Forum on Monetary Policy, Washington, D.C.

[9] Cogley, T. and T. Sargent (2003). "The Conquest of U.S. Inflation: Learning, Model Uncertainty, and Robustness." Working Paper, University of California, Davis and New York University. 
[10] Collard, F. and M. Juillard (2001a). "Accuracy of Stochastic Perturbation Methods: The Case of Asset Pricing Models." Journal of Economic Dynamics and Control, 25, pp. 979-999.

[11] Collard, F. and M. Juillard (2001b). "A Higher-Order Taylor Expansion Approach to Simulation of Stochastic Forward-Looking Models with an Application to a Non-Linear Phillips Curve." Computational Economics, pp. 125-139.

[12] Cooley, T. and E. Prescott (1995). "Economic Growth and Business Cycles." in T. Cooley (ed.), .Frontiers of Business Cycle Research, Princeton NJ: Princeton University Press.

[13] Demertzis, M. and A.F. Tieman, 2004, "Robust versus Optimal Rules in Monetary Policy: A Note," IMF Working Paper No. 04/96 (Washington, D.C.: International Monetary Fund).

[14] Elekdag, S. and I. Tchakarov (2004). "Balance Sheets, Exchange Rate Policy and Welfare," (unpublished; Washington, DC: International Monetary Fund).

[15] Erceg, C., D. Henderson and A. Levin (2000). "Optimal Monetary Policy with Staggered Wage and Price Contracts." Journal of Monetary Economics 46(2), pp. 281-313.

[16] Erceg, C. and A. Levin (2001). "Imperfect Credibility and Inflation Persistence," Working Paper, Board of Governors of the Federal Reserve System.

[17] Erceg, C., L. Guerrieri and C. Gust (2003). "SIGMA: A New Open Economy Model for Policy Analysis." Draft Paper prepared for the Annual Central Bank Modelers' Workshop, Amsterdam.

[18] Gali, J. (1999). "Technology, Employment, and the Business Cycle: Do Technology Shocks Explain Aggregate Fluctuations?" American Economic Review, March, pp. 249271. 
[19] Galí, J., M. Gertler, and J. D. López-Salido (2002). "Markups, Gaps, and the Welfare Costs of Business Fluctuations," National Bureau of Economic Research Working Paper No. 8850, March.

[20] Giannoni, M. P. and M. Woodford (2002a). "Optimal Interest-Rate Rules: I. General Theory." NBER Working Paper No. 9419 (Cambridge, Massachusetts: National Bureau of Economic Research).

[21] Giannoni, M. P. and M. Woodford (2002b). "Optimal Interest-Rate Rules: II. Applications.” NBER Working Paper No. 9420 (Cambridge, Massachusetts: National Bureau of Economic Research).

[22] Hall, R. (1988). "The Relation Between Price and Marginal Cost in U.S. Industry." Journal of Political Economy, Vol. 96, pp. 921-947.

[23] Hall, R., and C. Jones (1999). "Why do Some Countries Produce So Much More Output per Worker than Others?" Quarterly Journal of Economics, Vol. 114 (February), pp. 83-116.

[24] Hansen, L. P., and T. Sargent (2003). "Robust Control of Forward Looking Models." Journal of Monetary Economics, forthcoming.

[25] Ireland, P. (2001). "Sticky-Price Models of the Business Cycle: Specification and Stability." Journal of Monetary Economics 47, February, pp.3-18.

[26] Jean, S. and G. Nicoletti (2002). "Product market Regulation and Wage Premia in Europe and North America," OECD Economics Department Working Paper $\operatorname{ECO} / \mathrm{WKP}(2002) 4$.

[27] Juillard, M. (2004). "DYNARE: A Program for Simulating and Estimating SDGE Models." http://www.cepremap.cnrs.fr/dynare. 
[28] Kim, J. (2000). "Constructing and Estimating a Realistic Optimizing Model of Monetary Policy." Journal of Monetary Economics 45, April, pp. 329-359.

[29] Kim, J. and S. Kim (2003). "Welfare Effects of Tax Policy in Open Economies: Stabilization and Cooperation," (unpublished; Virginia: University of Virginia).

[30] Kim, J., S. Kim, E. Schaumburg and C. Sims (2003). "Calculating and Using Second Order Accurate Solutions of Discrete Time Dynamic Equilibrium Models," Draft, August 3, 2003, http://eco-072399b.princeton.edu/yftp/gensys2/Algorithm2.pdf

[31] Kollmann, R. (2002). "Monetary Policy in the Open Economy: Effects on Welfare and Business Cycles," Journal of Monetary Economics 49, pp. 989-1015.

[32] Lane, P. (2000). "The New Open Economy Macroeconomics: A Survey." Working Paper, Trinity College, Dublin.

[33] Laxton, D., and R. Tetlow (1992). "A Simple Multivariate Filter for the Measurement of Potential Output." Bank of Canada, Technical Report No. 59.

[34] Laxton, D., and P. N'Diaye (2002). "Monetary Policy Credibility and the Unemployment-Inflation Trade-off: Some Evidence from 17 Industrial Countries," Working Paper WP/02/220, International Monetary Fund.

[35] Laxton, D., and P. Pesenti (2003). "Monetary Policy Rules for Small, Open, Emerging Economies." Journal of Monetary Economics 50, July, pp. 1109-1146.

[36] Lucas, R.E. Jr. (2003). "Macroeconomic Priorities." Department of Economics, University of Chicago.

[37] Martins, J.O., S. Scarpetta, and D. Pilat (1996). "Mark-up Pricing, Market Structure and the Business Cycle." OECD Economic Studies 27 (II), pp.71-106.

[38] Orphanides, A. (2003). "Historical Monetary Policy Analysis and the Taylor Rule." Journal of Monetary Economics, Vol. 50, pp. 983-1022. 
[39] Pesenti, P. (2005). "The IMF Global Economy Model (GEM): Theoretical Framework", Working Paper, International Monetary Fund, forthcoming.

[40] Prescott, E.C. (2003). "Why Do Americans Work So Much More Than Europeans?," Federal Reserve Bank of Minneapolis, Research Department Staff Report 231, November.

[41] Roeger, W. (1995). "Can Imperfect Competition Explain the Difference Between Primal and Dual Productivity Measures? Estimates for U.S. Manufacturing." Journal of Political Economy 103, April, pp.316-330.

[42] Rotemberg, Julio J. (1982). "Sticky Prices in the United States." Journal of Political Economy 90, December, pp.1187-1211.

[43] Rotemberg, J.J. and M. Woodford (1998). "An Optimization-Based Econometric Model for the Evaluation of Monetary Policy." NBER Technical Working Paper no. 233, May.

[44] Rotemberg, J.J. and M. Woodford (1999). "Interest Rate Rules in an Estimated Sticky Price Model." In Monetary Policy Rules, ed. John B. Taylor. Chicago: University of Chicago Press, pp.57-119.

[45] Rudebusch, G.D. and L. E.O. Svensson (1999). "Policy Rules for Inflation Targeting." In Monetary Policy Rules, ed. John B. Taylor. Chicago: University of Chicago Press, pp.203-246.

[46] Rudebusch, G.D. (2002a). “Assessing Nominal Income Rules for Monetary Policy with Model and Data Uncertainty." Economic Journal, 112, pp.402-432.

[47] Rudebusch, G.D. (2002b). "Term Structure Evidence on Interest Rate Smoothing and Monetary Policy Inertia." Journal of Monetary Economics 49, pp.1161-1187.

[48] Schmitt-Grohe, S., and M. Uribe (2004). "Optimal Fiscal and Monetary Policy under Sticky Prices." Journal of Economic Theory, Vol. 114, February, pp.198-230. 
[49] Schorfheide, F. (2004). "Notes on Model Evaluation." Department of Economics, University of Pennsylvania.

[50] Sims, C. (2002). "The Role of Models and Probabilities in the Monetary Policy Process." Brookings Papers on Economic Activity, 2.

[51] Sims, C. (2003). "Matlab Procedures to Compute Marginal Data Densities for VARs with Minnesota and Training Sample Priors." Department of Economics, Princeton.

[52] Sims, C. and T. Zha (1998). "Bayesian Methods for Dynamic Multivariate Models." International Economic Review, 49, pp. 949-968.

[53] Smets, F. and R. Wouters (2004). "Shocks and Frictions in Business Cycles: A Bayesian DSGE Approach.” Working Paper, European Central Bank and the National Bank of Belgium.

[54] Straub, R. and I. Tchakarov (2004). "Non-fundamental Exchange Rate Volatility and Welfare," ECB Working Paper No. 328 (Frankfurt, Germany: European Central Bank).

[55] Svensson, L E.O. (1999a). "Inflation Targeting as a Monetary Policy Rule." Journal of Monetary Economics, 43, pp. 607-654.

[56] Svensson, L E.O. (1999b). "How Should Monetary Policy Be Conducted in an Era of Price Stability?" In New Challenges for Monetary Policy. Federal Reserve Bank of Kansas City, Kansas City, pp. 195-259.

[57] Svensson, L E.O. (2003a). "The Inflation Forecast and the Loss Function." Central Bank Banking Monetary Theory and Practice: Essays in Honour of Charles Goodhart, in Paul Mizen, ed., Volume I, Edward Elgar, pp. 135-152.

[58] Svensson, L E.O. (2003b). "What Is Wrong with Taylor Rules? Using Judgment in Monetary Policy through Targeting Rules." Journal of Economic Literature, 41 (2003) 426-477 
[59] Svensson, L E.O.and M. Woodford (2003). "Implementing Optimal Policy through Inflation-Forecast Targeting." NBER Working Paper No. 9747.

[60] Svensson, L E.O.and M. Woodford (2003). "Indicator Variables for Optimal Policy." Journal of Monetary Economics, 50 (2003), pp. 691-720.

[61] Taylor, J. (1993). "Discretion Versus Policy Rules in Practice." Carnegie-Rochester Conference Series on Public Policy, Vol. 39, pp. 195-214.

[62] Williams, J. (2003). "Simple Rules for Monetary Policy." FRBSF Economic Review, 2003.

[63] Woodford, M. (2001). "The Taylor Rule and Optimal Monetary Policy." American Economic Review, 91(2), pp. 231-237.

[64] Woodford, M. (2003a). "Optimal Monetary Policy Inertia." Review of Economic Studies, vol. 70 , pp. 861-886.

[65] Woodford, M. (2003b). Interest and Prices. Foundations of a Theory of Monetary Policy. Princeton, NJ: Princeton University Press. 
Table 1: Assumptions About Parameters and Steady-State Ratios

\begin{tabular}{lc}
\hline Parameters: & Value \\
Discount Rate $\beta$ & $1.04^{-.25}$ \\
Capital Depreciation Rate $\delta$ & 0.025 \\
Elasticity of Substitution between Capital and Labor & 0.99 \\
Intertemporal Elasticity of Substitution $1 / \sigma$ & 0.80 \\
Inverse of Frisch Elasticity of Labor Supply $\zeta$ & 3.00 \\
Weight of Capital in Production Technology & 0.70 \\
Steady-State Elasticity of Substitution among Labor Inputs $\psi_{S S}$ & 7.25 \\
Steady-State Elasticity of Substitution among Goods $\theta_{S S}$ & 5.35 \\
Steady-State Ratios: & \\
Labor's Income Share & 0.58 \\
Consumption-to-GDP Ratio & 0.65 \\
Investment-to-GDP Ratio & 0.17 \\
Government Spending-to-GDP Ratio & 0.18 \\
Annual Capital-to-GDP Ratio & 1.70 \\
Wage Markup $\psi_{S S} /\left(\psi_{S S}-1\right)$ & 1.16 \\
Price Markup $\theta_{S S} /\left(\theta_{S S}-1\right)$ & 1.23 \\
\hline
\end{tabular}

Table 2: Losses as a Result of Imperfect Competition in Product and Labor Markets 
Table 3: Specification of the Stochastic Processes

\begin{tabular}{lc}
\hline Assumptions about the Shocks & Stochastic Processes \\
\hline Demand Shocks: & \\
Government Absorption & $\log \left(G_{t}\right)=\left(1-\lambda_{G C}\right) \log \left(G_{S S}\right)+\lambda_{G C} \log \left(G_{t-1}\right)+\varepsilon_{G, t}$ \\
Investment & $\log \left(1+Z_{I, t}\right)=\left(1-\lambda_{Z I}\right) \log \left(1+Z_{I, S S}\right)+\lambda_{Z I} \log \left(1+Z_{I, t-1}\right)+\varepsilon_{Z I, t}$ \\
Marginal Utility & $Z_{U, t}=\left(1-\lambda_{Z U}\right) Z_{U, S S}+\lambda_{Z U} Z_{U, t-1}+\varepsilon_{Z U, t}$ \\
Reaction Function & $Z_{i, t}=\lambda_{i} Z_{i, t-1}+\varepsilon_{i, t}$ \\
Supply Shocks: & \\
Productivity & \\
Labor Supply & $Z_{T, t}=\left(1-\lambda_{Z T}\right) Z_{T, S S}+\lambda_{Z T} Z_{T, t-1}+\varepsilon_{Z T, t}$ \\
Price Markup & $Z_{V, t}=\left(1-\lambda_{Z V}\right) Z_{V, S S}+\lambda_{V} Z_{V, t-1}+\varepsilon_{Z V, t}$ \\
Wage Markup & $\log \left(\theta_{t}-1\right)=\log \left(\theta_{S S}-1\right)+\varepsilon_{\theta, t}$ \\
& $\log \left(\psi_{t}-1\right)=\log \left(\psi_{S S}-1\right)+\varepsilon_{\psi, t}$ \\
\hline
\end{tabular}

Table 4: Estimation Results

Parameters

\begin{tabular}{cccccc}
\hline & Prior & Mean Estimate & $90 \%$ Interval & Density & Std \\
\hline$b_{C}$ & 0.90 & 0.83 & $0.75-0.90$ & Beta & 0.05 \\
$b_{l}$ & 0.75 & 0.72 & $0.65-0.81$ & Beta & 0.05 \\
$\phi_{W}$ & 1.40 & 1.41 & $1.25-1.57$ & Norm & 0.10 \\
$\phi_{Q}$ & 1.40 & 1.37 & $1.20-1.52$ & Norm & 0.10 \\
$\omega_{i}$ & 0.80 & 0.72 & $0.60-0.84$ & Beta & 0.10 \\
$\omega_{1}$ & 0.50 & 0.52 & $0.37-0.64$ & Norm & 0.10 \\
$\omega_{2}$ & 0.25 & 0.34 & $0.25-0.41$ & Norm & 0.10 \\
$\omega_{3}$ & 0.25 & 0.14 & $0.05-0.25$ & Norm & 0.10 \\
$\phi_{I_{1}}$ & 1.00 & 1.01 & $0.87-1.18$ & Norm & 0.10 \\
$\phi_{I_{2}}$ & 80.00 & 77.97 & $65.06-90.44$ & Norm & 8.00 \\
\hline$\phi_{L}$ & 0.50 & 0.51 & $0.35-0.67$ & Norm & 1.00 \\
\hline
\end{tabular}


Table 5: Estimation Results Continued Parameters

\begin{tabular}{lccccc}
\hline & Prior & Estimate & $90 \%$ Interval & Density & Std \\
\hline$\lambda_{G C}$ & 0.85 & 0.95 & $0.91-0.99$ & Beta & 0.10 \\
$\lambda_{Z T}$ & 0.85 & 0.89 & $0.82-0.98$ & Beta & 0.10 \\
$\lambda_{Z U}$ & 0.85 & 0.88 & $0.82-0.94$ & Beta & 0.10 \\
$\lambda_{Z V}$ & 0.85 & 0.87 & $0.74-0.99$ & Beta & 0.10 \\
$\lambda_{Z I}$ & 0.85 & 0.68 & $0.58-0.79$ & Beta & 0.10 \\
$\lambda_{i}$ & 0.85 & 0.78 & $0.68-0.91$ & Beta & 0.10 \\
\hline
\end{tabular}

Table 6: Estimation Results Continued

Standard Deviation of Shocks

\begin{tabular}{lccccc}
\hline & Prior & Estimate & $90 \%$ Interval & Density & Std \\
\hline$\sigma_{\epsilon_{Z T}}$ & 0.010 & 0.0039 & $0.0031-0.0046$ & Invg & Inf \\
$\sigma_{\epsilon_{Z U}}$ & 0.010 & 0.0230 & $0.0158-0.0303$ & Invg & Inf \\
$\sigma_{\epsilon_{Z V}}$ & 0.010 & 0.0384 & $0.0024-0.0194$ & Invg & Inf \\
$\sigma_{\varepsilon_{Z I}}$ & 0.050 & 0.0447 & $0.0349-0.0540$ & Invg & Inf \\
$\sigma_{\varepsilon_{\psi}}$ & 1.000 & 3.1390 & $3.8642-7.0061$ & Invg & Inf \\
$\sigma_{\epsilon_{\theta}}$ & 1.000 & 0.7356 & $0.5701-0.9218$ & Invg & Inf \\
$\sigma_{\epsilon_{i}}$ & 0.010 & 0.0039 & $0.0031-0.0046$ & Invg & Inf \\
$\sigma_{\epsilon_{G C}}$ & 0.010 & 0.0089 & $0.0069-0.0108$ & Invg & Inf \\
\hline$\sigma_{\epsilon_{Z U}}, \epsilon_{Z I}$ & 0.750 & 0.7643 & $0.6520-0.8852$ & Beta & 0.10 \\
\hline
\end{tabular}

Table 7: Estimation Results Continued Standard Deviation of Measurment Errors

\begin{tabular}{lccccc}
\hline & Prior & Estimate & $90 \%$ Interval & Density & Std \\
\hline GDP & 0.10 & 0.1482 & $0.1038-0.1933$ & Invg & Inf \\
Consumption & 0.10 & 0.2537 & $0.2060-0.2973$ & Invg & Inf \\
Investment & 0.10 & 0.9763 & $0.7658-1.1916$ & Invg & Inf \\
Real Wage & 0.10 & 0.5648 & $0.4532-0.6301$ & Invg & Inf \\
Hours & 0.10 & 0.0598 & $0.0260-0.0920$ & Invg & Inf \\
Inflation $(Q A R)$ & 0.10 & 0.1952 & $0.0244-0.4101$ & Invg & Inf \\
Fed Funds Rate & 0.10 & 0.0738 & $0.0277-0.1169$ & Invg & Inf \\
\hline
\end{tabular}


Table 8: Estimation Results Continued Variance Decompositions (Demand Shocks)

\begin{tabular}{cccc}
\hline & GDP & Inflation & Fed Funds Rate \\
\hline$\sigma_{\epsilon_{Z U}}$ & 26.8 & 7.2 & 45.8 \\
$\sigma_{\varepsilon_{Z I}}$ & 11.0 & 1.8 & 8.9 \\
$\sigma_{\epsilon_{i}}$ & 2.8 & 9.6 & 8.0 \\
$\sigma_{\epsilon_{G C}}$ & 0.5 & 0.2 & 0.7 \\
\hline Sum & 41.1 & 18.8 & 63.4 \\
\hline
\end{tabular}

Table 9: Estimation Results Continued Variance Decompositions (Supply Shocks)

\begin{tabular}{cccc}
\hline & GDP & Inflation & Fed Funds Rate \\
\hline$\sigma_{\epsilon_{Z T}}$ & 5.3 & 7.1 & 3.4 \\
$\sigma_{\epsilon_{Z V}}$ & 49.7 & 37.4 & 17.1 \\
$\sigma_{\varepsilon_{\psi}}$ & 0.1 & 0.2 & 0.1 \\
$\sigma_{\epsilon_{\theta}}$ & 3.8 & 36.6 & 16.0 \\
\hline Sum & 58.9 & 81.2 & 36.6 \\
\hline
\end{tabular}


Table 10: Comparison of Marginal Likelihoods with Other Models

\begin{tabular}{lc}
\hline & Marginal Likelihood \\
\hline BVAR (1 lag) & -632.96 \\
BVAR (2 lag) & -603.36 \\
BVAR (3 lag) & -603.58 \\
BVAR (4 lag) & -607.61 \\
BVAR (5 lag) & -610.45 \\
BVAR (6 lag) & -618.22 \\
BVAR (7 lag) & -623.78 \\
BVAR (8 lag) & -629.18 \\
SW(2004) Model & -611.56 \\
Base-Case Model & -596.03 \\
\hline
\end{tabular}

Table 11: Comparison of marginal likelihoods with restrictions on the DSGE model

\begin{tabular}{lc}
\hline & Marginal Likelihood \\
\hline Base-Case Model & -596.03 \\
Orphanides $(2003)$ Reaction Function & -605.50 \\
No Inertia in the Reaction Function $\left(\omega_{i}=0\right)$ & -610.33 \\
No Nominal Rigidities $\left(\phi_{W_{2}}=\phi_{Q_{2}}=0\right)$ & -759.05 \\
Double Nominal Rigidities $\left(\phi_{W_{2}}=\phi_{Q_{2}}=2.8\right)$ & -599.65 \\
Halve Nominal Rigidities $\left(\phi_{W_{2}}=\phi_{Q_{2}}=0.7\right)$ & -595.06 \\
No Correlation between Consumption and Investment Shocks $\left(\sigma_{\epsilon_{Z U}, \epsilon_{Z I}}=0\right)$ & -601.40 \\
No Adjustment Costs on Capital $\left(\phi_{I_{1}}=0\right)$ & -596.75 \\
\hline
\end{tabular}


Table 12: Estimation Results Continued Comparison of the Two SWB Rules

\begin{tabular}{lcccc}
\hline & SWB1 & SWB2 & SWB1 & SWB2 \\
\hline & Mean & Mean & Std. & Std. \\
\hline Changes in Fed Funds Rate & 0.0 & 0.0 & 0.5 & 1.0 \\
Welfare & -14.92 & -14.69 & & \\
GDP & 18.4 & 18.8 & 2.1 & 1.4 \\
Consumption & 22.0 & 22.3 & 2.2 & 1.9 \\
Investment & 23.4 & 24.8 & 8.3 & 6.1 \\
Hours & 16.0 & 16.1 & 2.2 & 1.6 \\
Real Wage & 7.3 & 7.6 & 2.04 & 1.9 \\
Inflation Y-O-Y & 0.0 & 0.0 & 1.4 & 2.2 \\
\hline
\end{tabular}


Figure 1: Estimates of Trend and Detrended Series

\section{US}

Solid=actual, dashed=trend
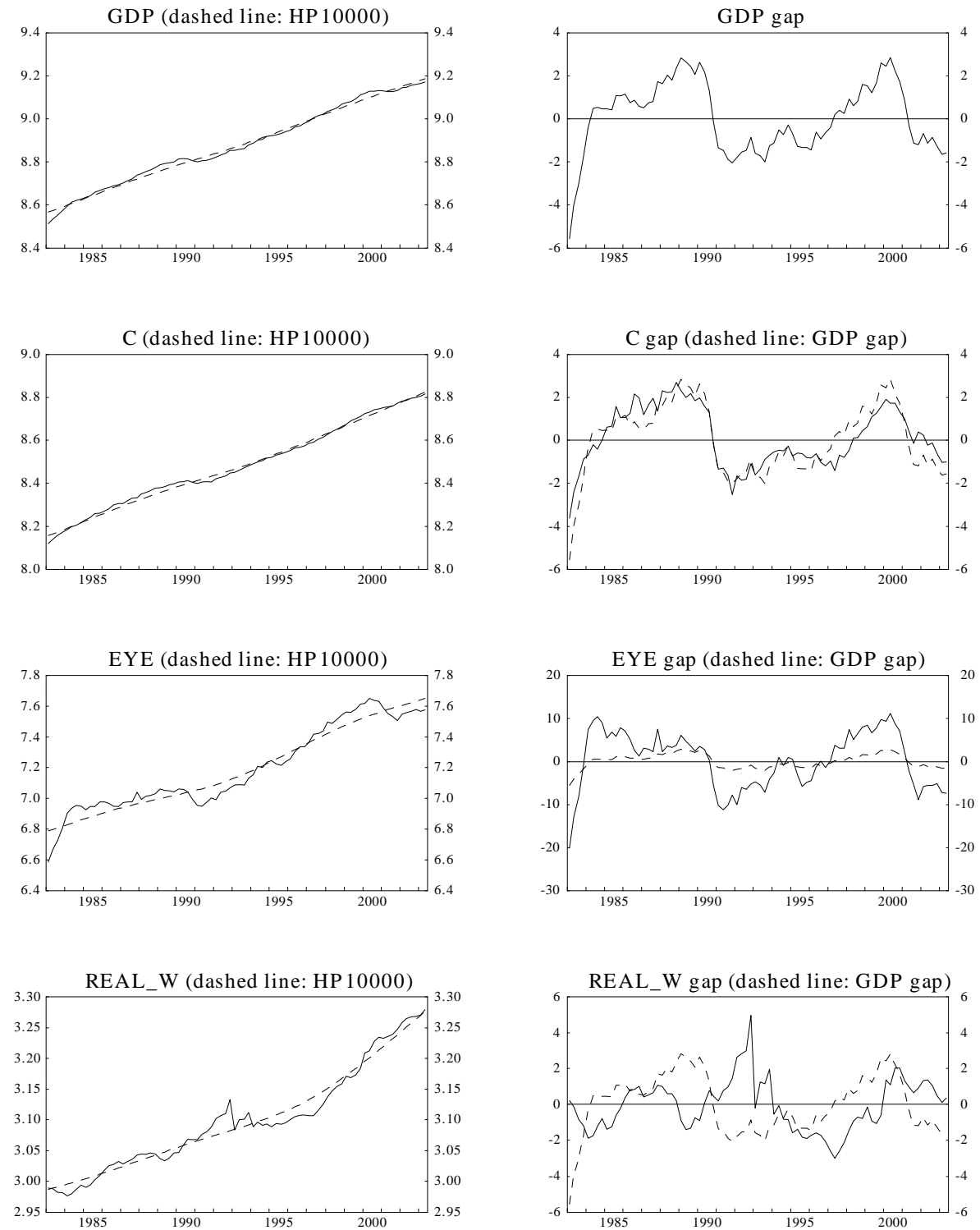
Figure 2: Estimates of Trend and Detrended Series (Continued)

\section{US}

Solid=actual, ashed $=$ trend
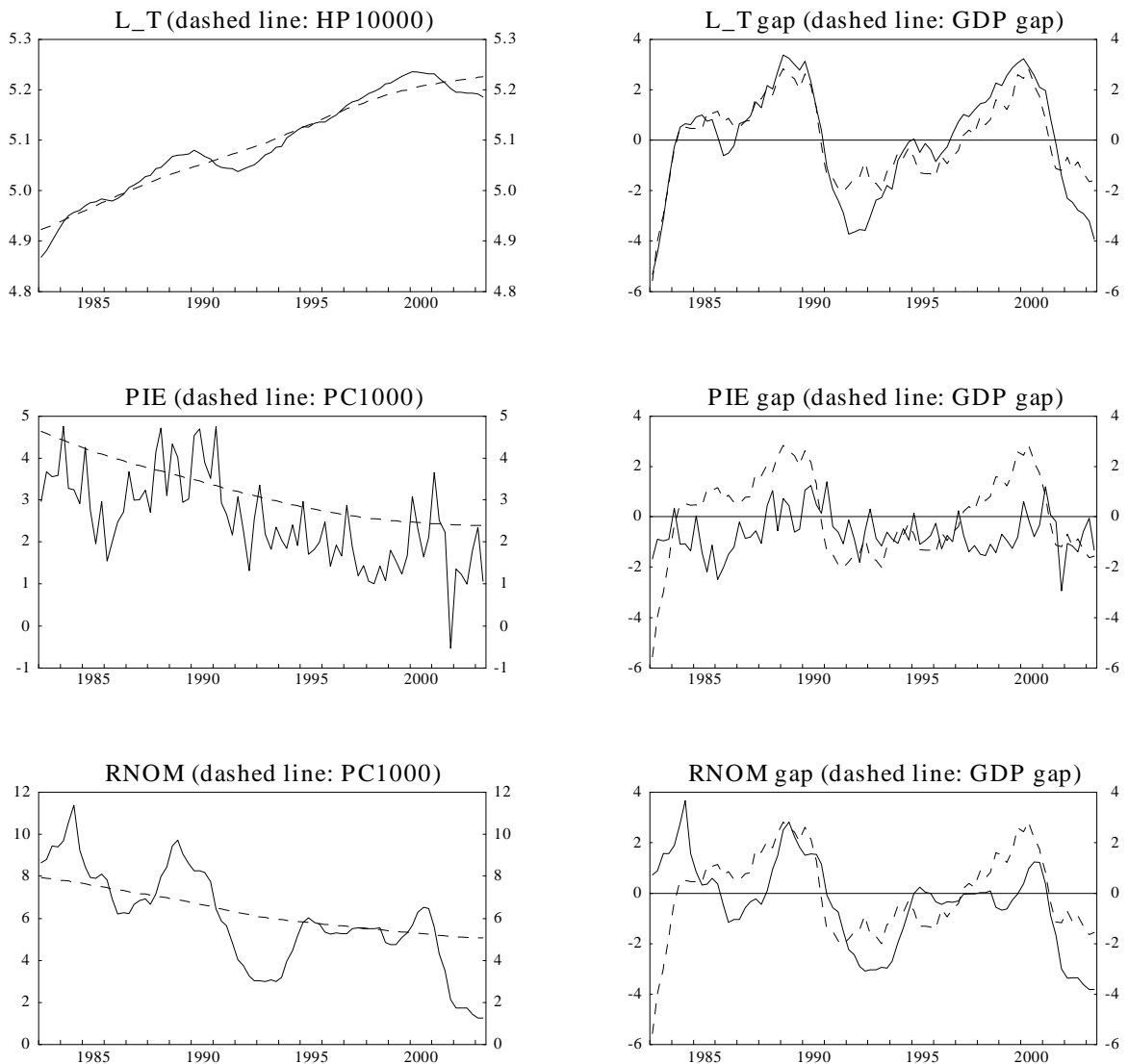
Figure 3: Shock to the Fed Funds Rate (Demand)

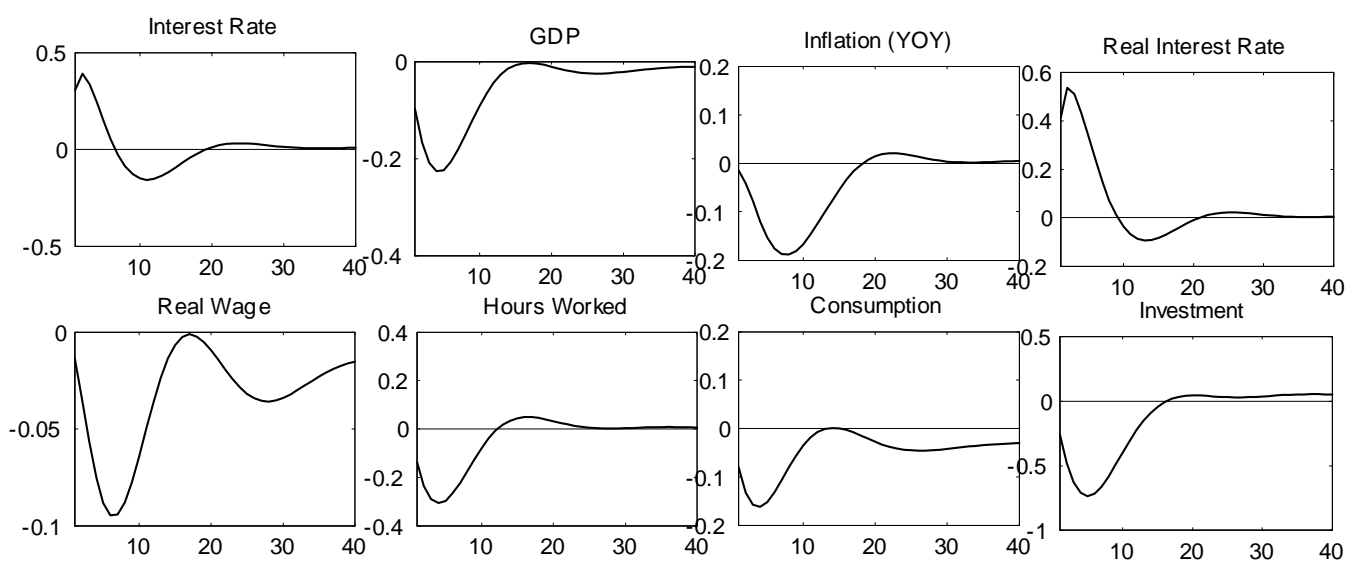

Figure 4: Shock to Government Absorption (Demand)
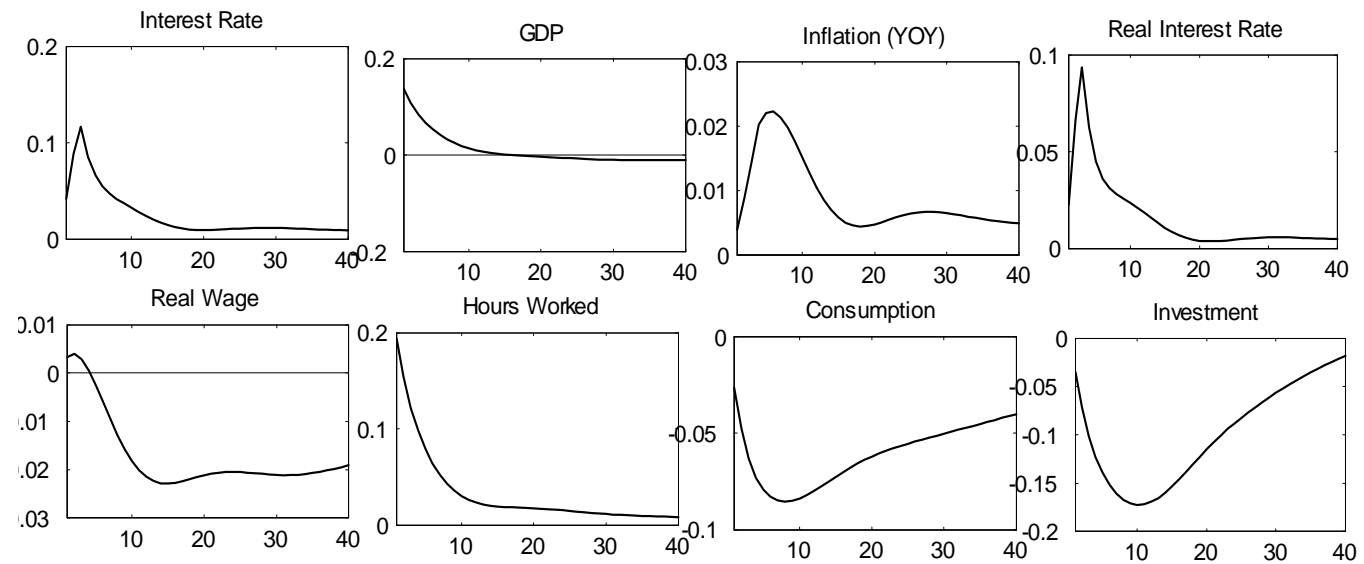
Figure 5: Shock to the Marginal Utility of Consumption (Demand)
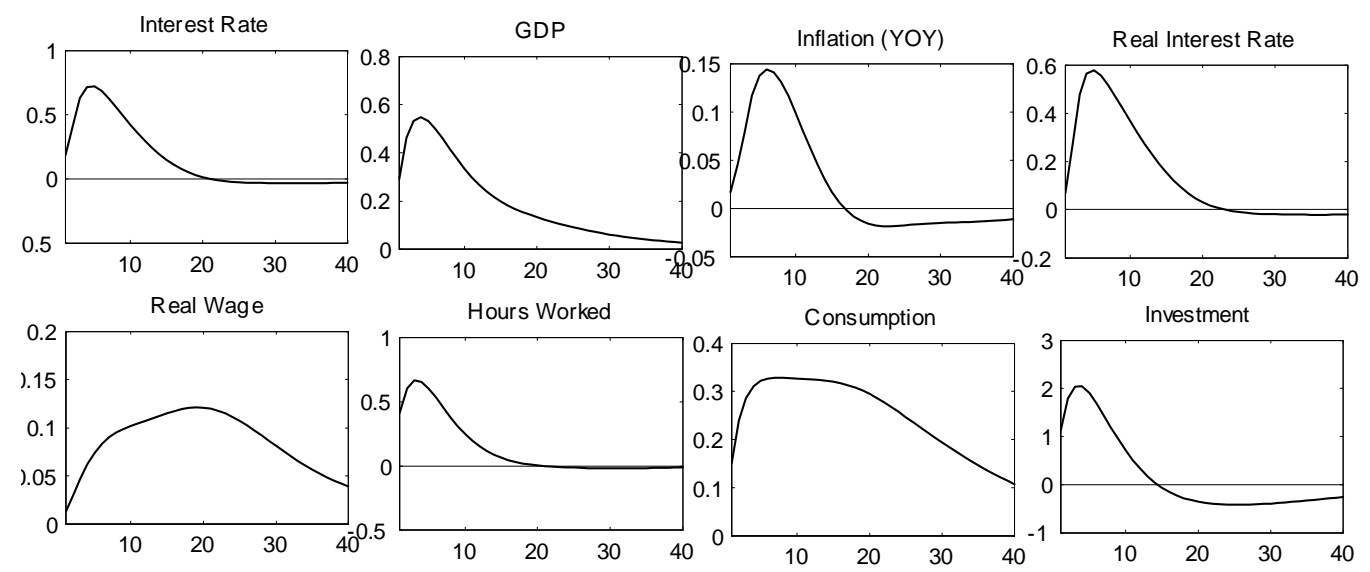

Figure 6: Shock to Investment (Demand)
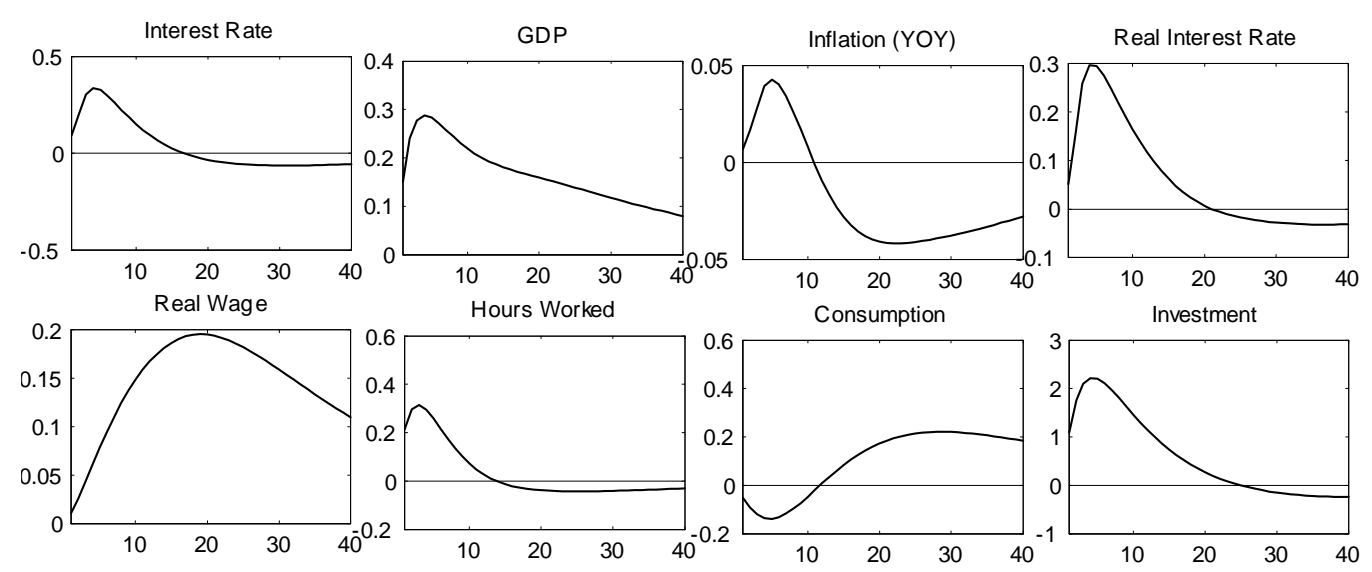
Figure 7: Negative Shock to the Wage Markup (Supply)
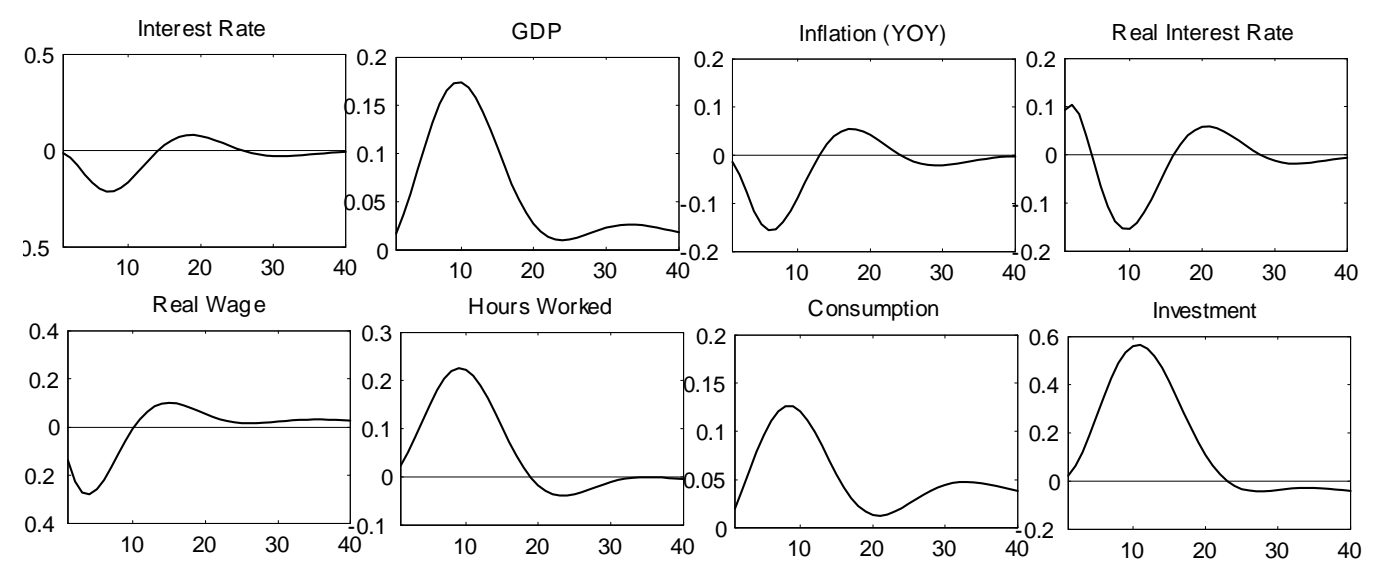

Figure 8: Negative Shock to the Price Markup (Supply)
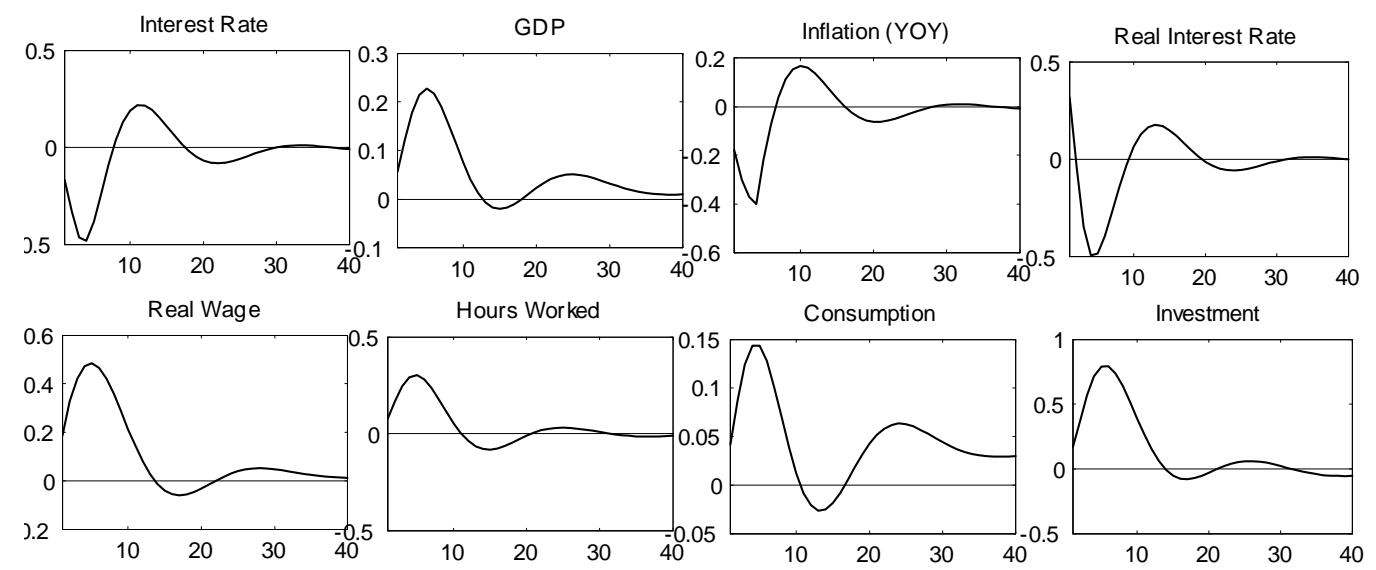
Figure 9: Shock to Productivity (Supply)
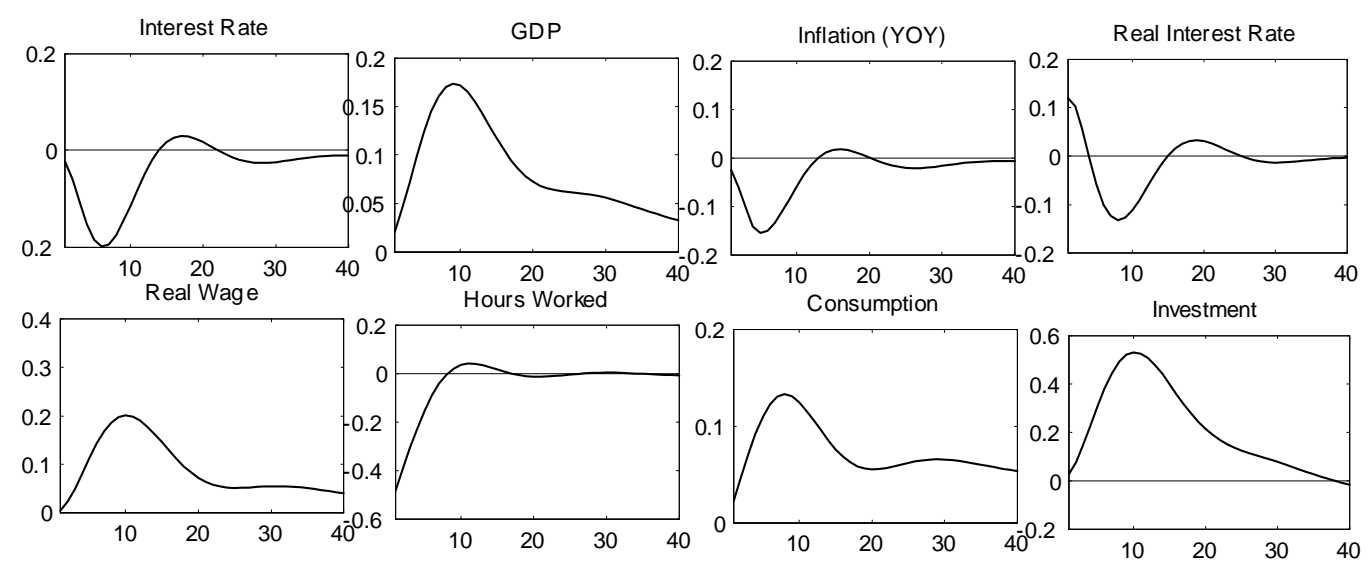

Figure 10: Shock to the Labor Effort (Supply)
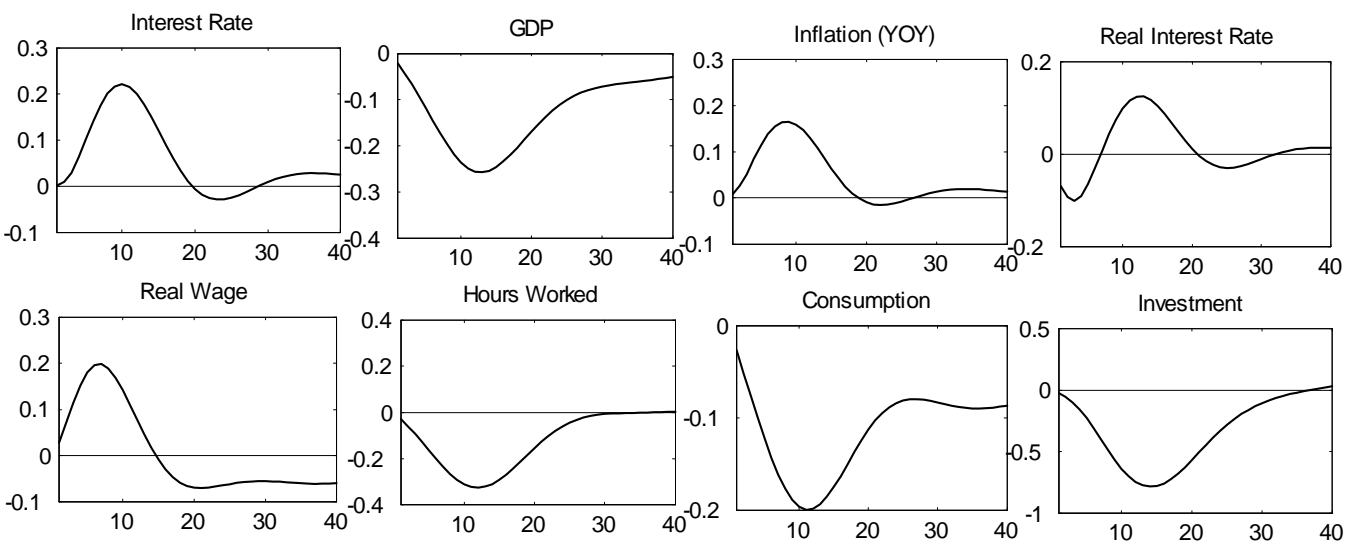
Figure 11: Comparison of Actual and Fitted Values
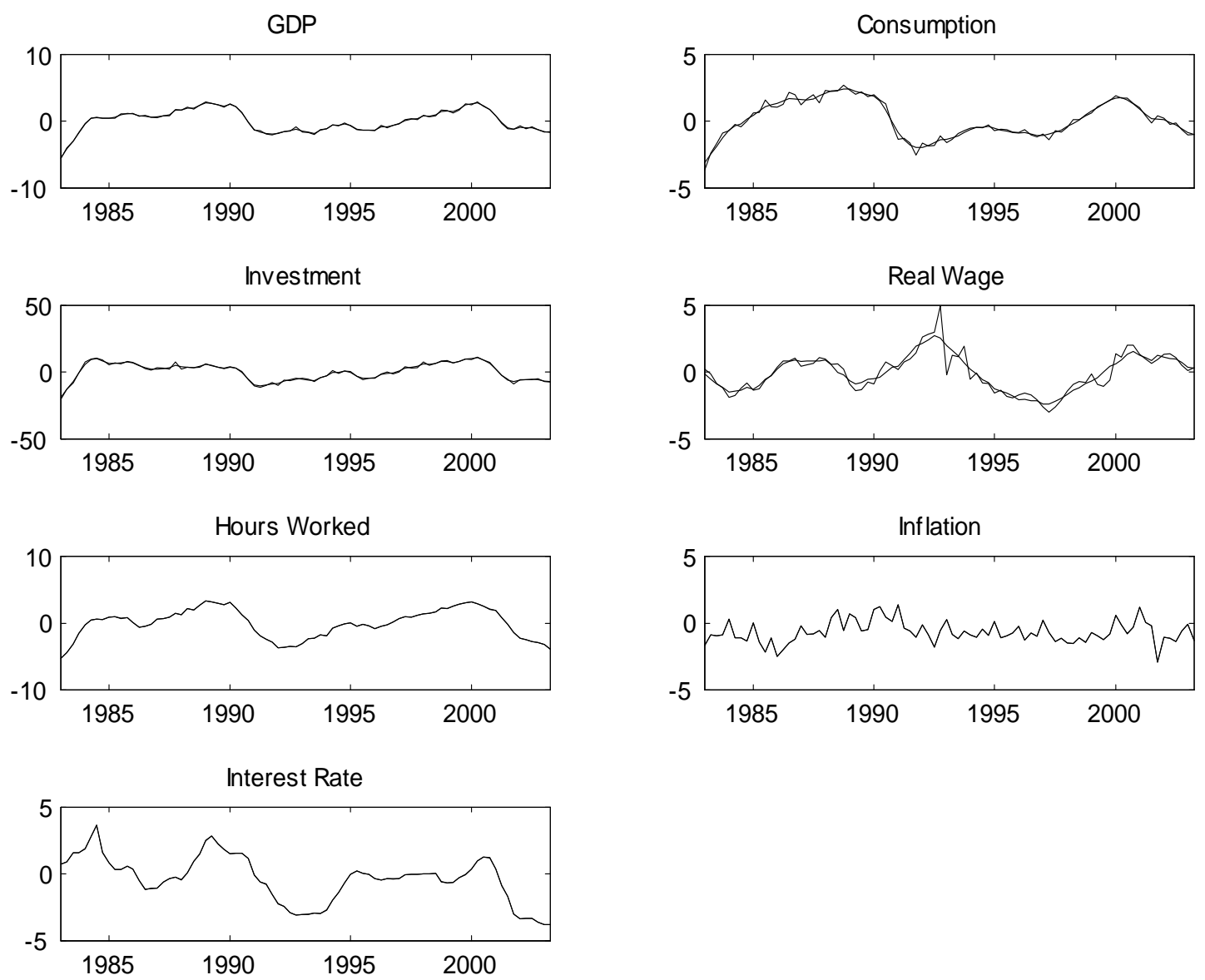
Figure 12: Historical Structural Shocks
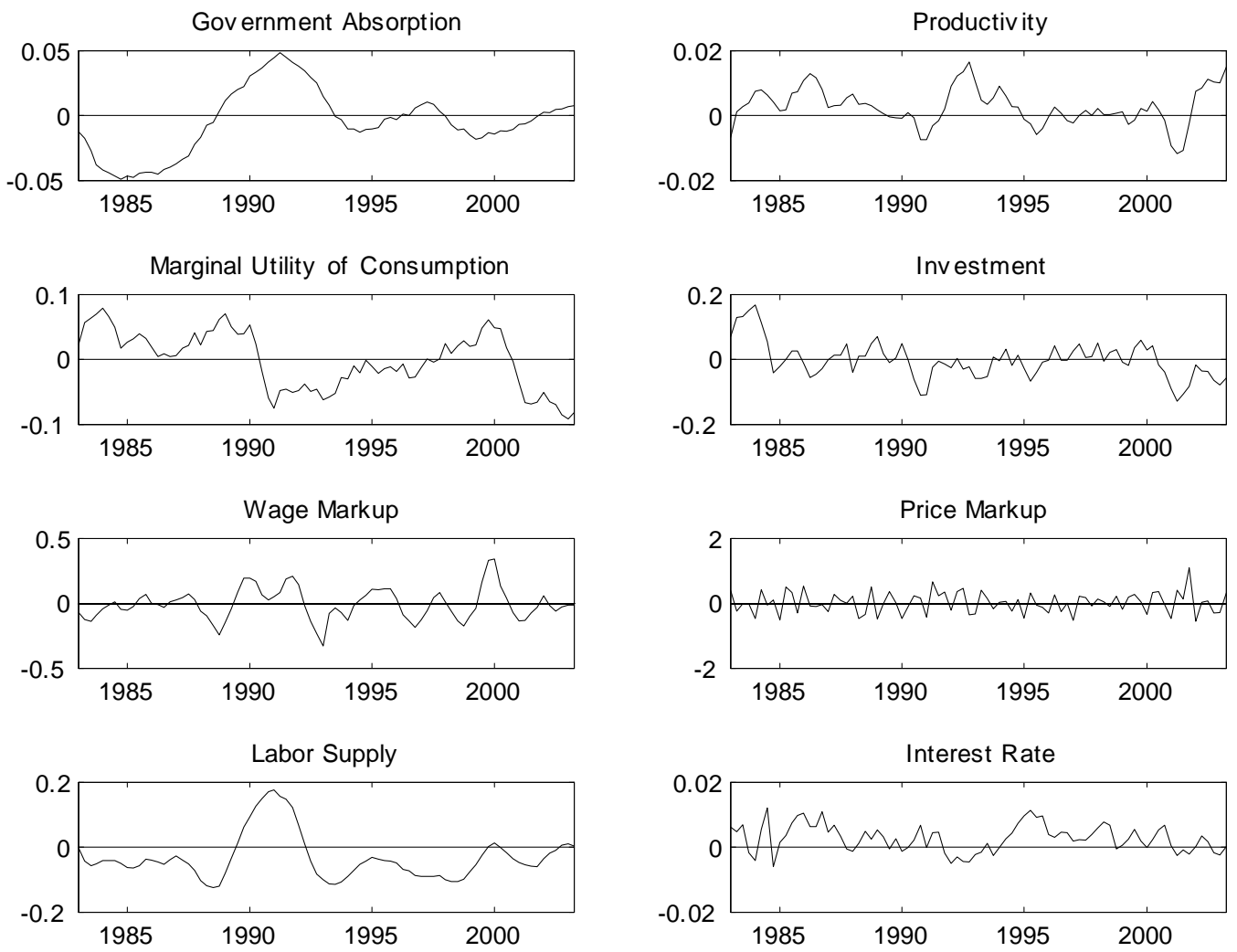
Figure 13: Taylor Efficiency Frontiers: Two Assumptions about Interest Rate Variability Note: The two frontiers plot the standard deviations for inflation and output under the constraints imposed on the standard deviation in the first difference of the Fed funds rate (0.5 and 1.0, dashed and solid lines, respectively). SWB1 and SWB2, the two simple-welfare-based-rules denoted by the two dark dots, lie almost directly on the solid and dashed frontiers respectively. The numbers as a caption next to each SWB rule denote the weights of the interest rule as indicated below.

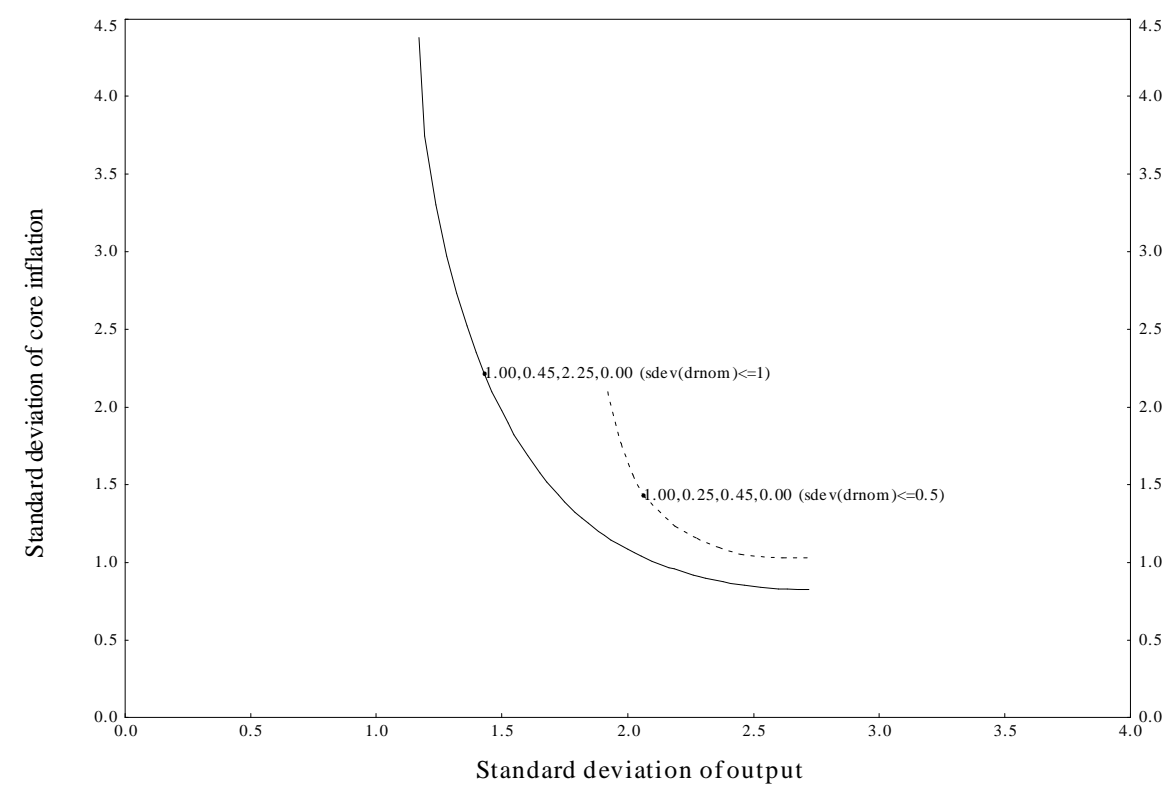

Labels: (Lagged Interest Rate weight, Inflation weight, Output Growth weight, Output Level weight, Constraint on the std dev of the change in interest rate 
Figure 14: Permanent Losses in Consumption From Choosing a Suboptimal Point on the Frontier: Two Assumptions about Interest Rate Variability

Note: Welfare is measured in terms of consumption equivalent units, denoted by (CONEQUIV) and the label $(\mathrm{CONCPCT})$ on the vertical axis is the percent deviation (in consumption utils terms) from the deterministic steady state consumption in the model (C_SS). Hence, CONPCT $=100 *(($ CONEQUIV-C_SS $) /$ C_SS $)$

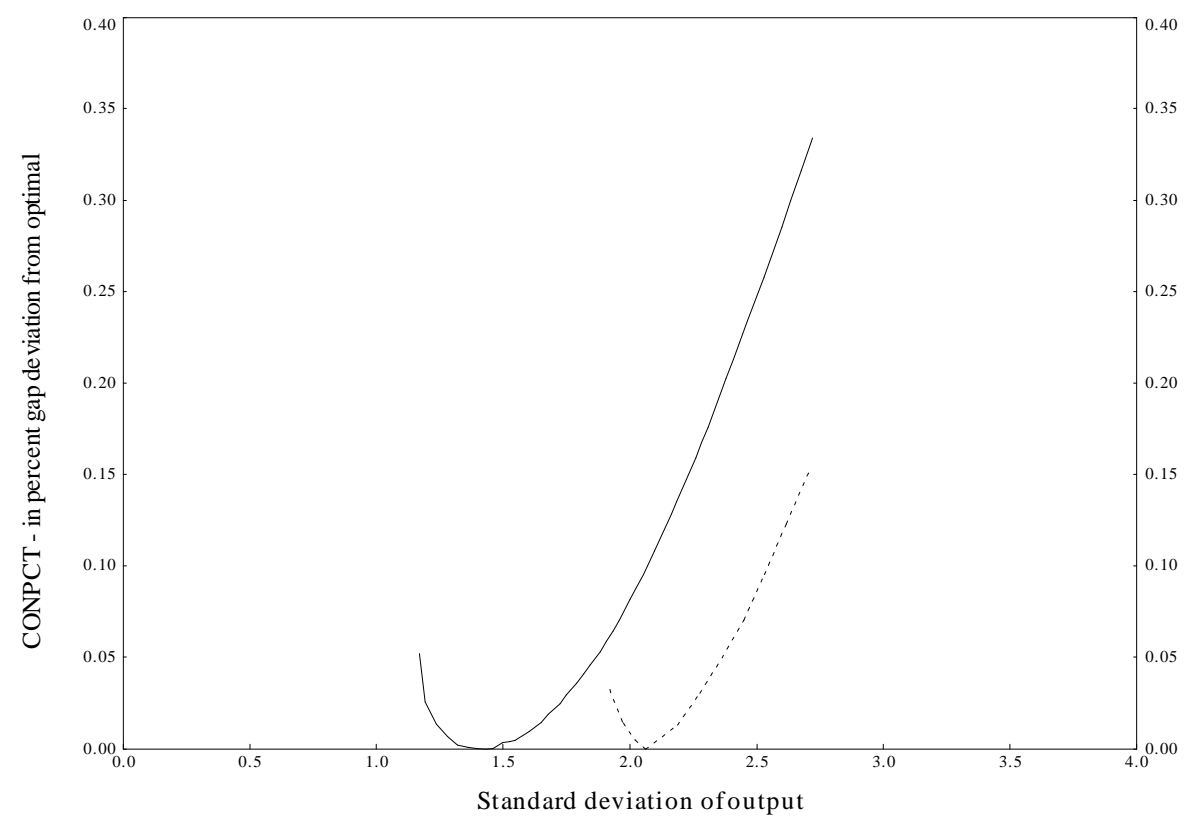


Figure 15: Inflation and the Output Gap Under the Base-Case SWB1 Rule
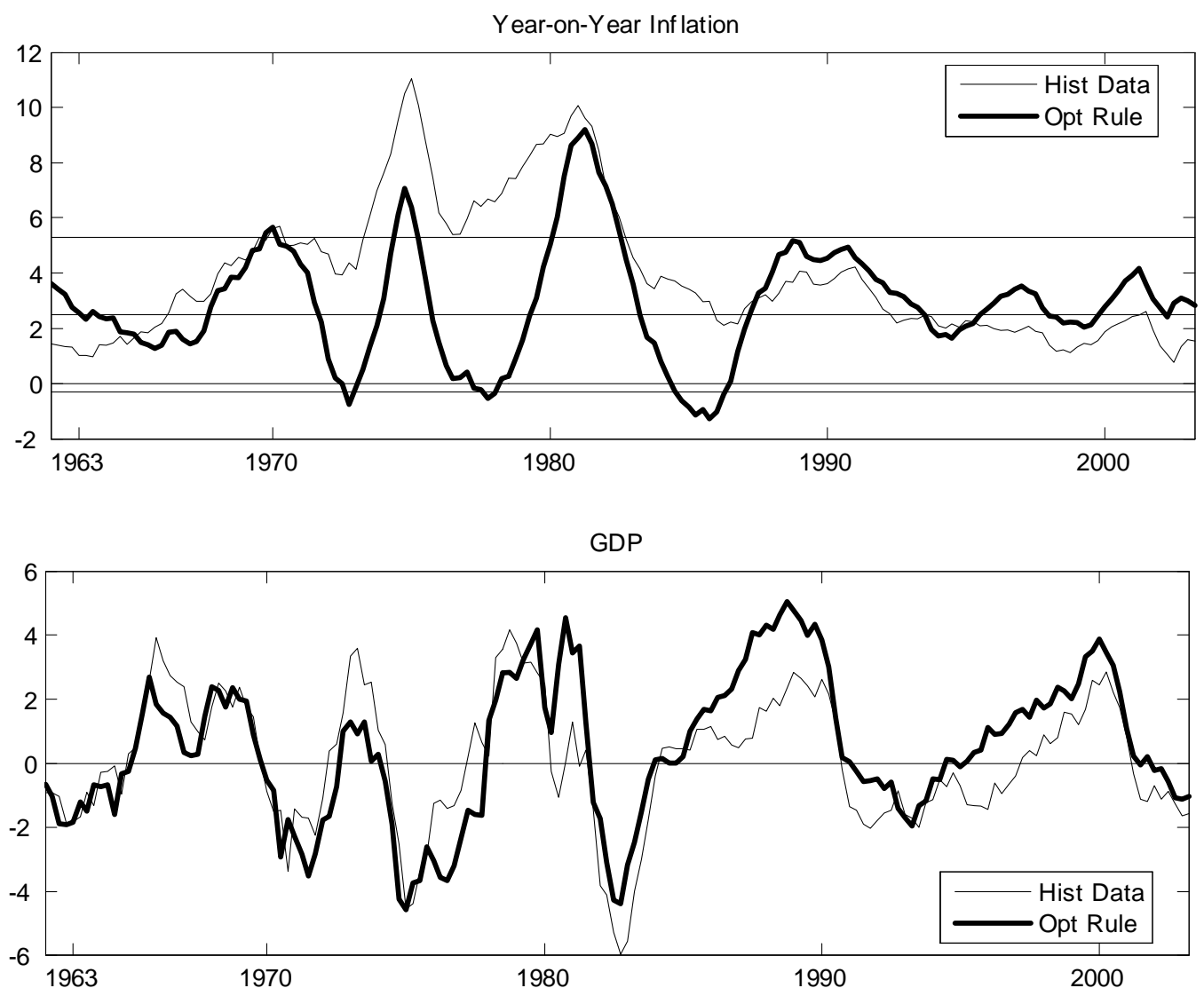
Figure 16: Inflation and the Output Gap Under the More Aggressive SWB2 Rule
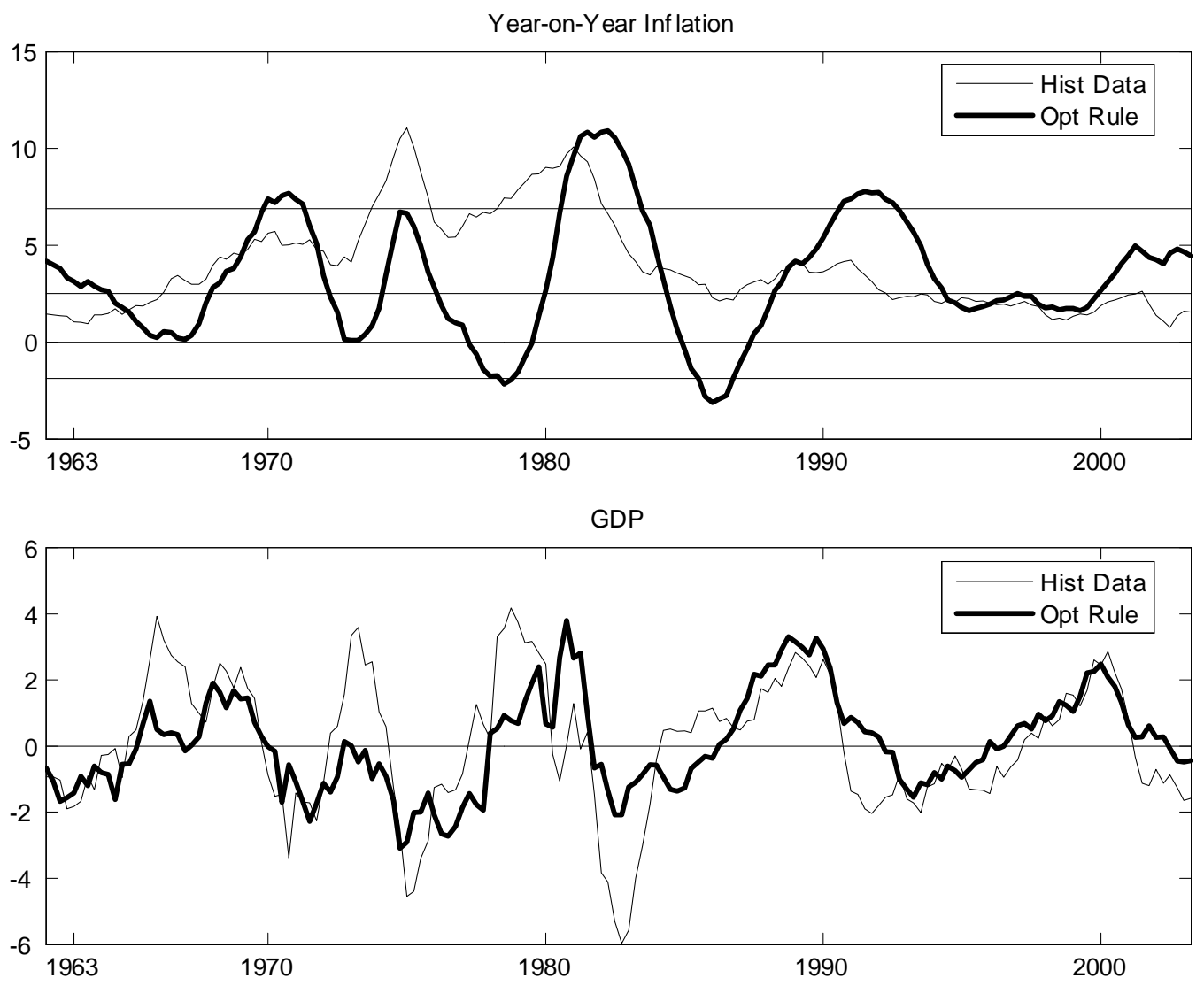


\section{European Central Bank Working Paper Series}

For a complete list of Working Papers published by the ECB, please visit the ECB's website (http://www.ecb.int)

570 "Household debt sustainability: what explains household non-performing loans? An empirical analysis” by L. Rinaldi and A. Sanchis-Arellano, January 2006.

57I “Are emerging market currency crises predictable? A test” by T. A. Peltonen, January 2006.

572 "Information, habits, and consumption behavior: evidence from micro data" by M. Kuismanen and L. Pistaferri, January 2006.

573 "Credit chains and the propagation of financial distress" by F. Boissay, January 2006.

574 "Inflation convergence and divergence within the European Monetary Union" by F. Busetti, L. Forni, A. Harvey and F. Venditti, January 2006.

575 "Growth in euro area labour quality" by G. Schwerdt and J. Turunen, January 2006.

576 “Debt stabilizing fiscal rules” by P. Michel, L. von Thadden and J.-P. Vidal, January 2006.

577 "Distortionary taxation, debt, and the price level" by A. Schabert and L. von Thadden, January 2006.

578 "Forecasting ECB monetary policy: accuracy is (still) a matter of geography" by H. Berger, M. Ehrmann and M. Fratzscher, January 2006.

579 "A disaggregated framework for the analysis of structural developments in public finances" by J. Kremer, C. Rodrigues Braz, T. Brosens, G. Langenus, S. Momigliano and M. Spolander, January 2006.

580 "Bank interest rate pass-through in the euro area: a cross country comparison" by C. K. Sørensen and T. Werner, January 2006.

58I "Public sector efficiency for new EU Member States and emerging markets" by A. Afonso, L. Schuknecht and V. Tanzi, January 2006.

582 "What accounts for the changes in U.S. fiscal policy transmission?" by F. O. Bilbiie, A. Meier and G. J. Müller, January 2006.

583 "Back to square one: identification issues in DSGE models" by F. Canova and L. Sala, January 2006.

584 “A new theory of forecasting” by S. Manganelli, January 2006.

585 "Are specific skills an obstacle to labor market adjustment? Theory and an application to the EU enlargement" by A. Lamo, J. Messina and E. Wasmer, February 2006.

586 "A method to generate structural impulse-responses for measuring the effects of shocks in structural macro models" by A. Beyer and R. E. A. Farmer, February 2006. 
587 "Determinants of business cycle synchronisation across euro area countries" by U. Böwer and C. Guillemineau, February 2006.

588 "Rational inattention, inflation developments and perceptions after the euro cash changeover" by M. Ehrmann, February 2006.

589 "Forecasting economic aggregates by disaggregates" by D. F. Hendry and K. Hubrich, February 2006.

590 "The pecking order of cross-border investment" by C. Daude and M. Fratzscher, February 2006.

591 "Cointegration in panel data with breaks and cross-section dependence" by A. Banerjee and J. L. Carrion-i-Silvestre, February 2006.

592 "Non-linear dynamics in the euro area demand for MI" by A. Calza and A. Zaghini, February 2006.

593 “Robustifying learnability” by R. J. Tetlow and P. von zur Muehlen, February 2006.

594 “The euro's trade effects” by R. Baldwin, comments by J. A. Frankel and J. Melitz, March 2006.

595 "Trends and cycles in the euro area: how much heterogeneity and should we worry about it?" by D. Giannone and L. Reichlin, comments by B. E. Sørensen and M. McCarthy, March 2006.

596 "The effects of EMU on structural reforms in labour and product markets" by R. Duval and J. Elmeskov, comments by S. Nickell and J. F. Jimeno, March 2006.

597 "Price setting and inflation persistence: did EMU matter?" by I. Angeloni, L. Aucremanne, M. Ciccarelli, comments by W. T. Dickens and T. Yates, March 2006.

598 "The impact of the euro on financial markets" by L. Cappiello, P. Hördahl, A. Kadareja and S. Manganelli, comments by X. Vives and B. Gerard, March 2006.

599 "What effects is EMU having on the euro area and its Member Countries? An overview" by F. P. Mongelli and J. L. Vega, March 2006.

600 “A speed limit monetary policy rule for the euro area” by L. Stracca, April 2006.

601 "Excess burden and the cost of inefficiency in public services provision" by A. Afonso and V. Gaspar, April 2006.

602 "Job flow dynamics and firing restrictions: evidence from Europe" by J. Messina and G. Vallanti, April 2006.

603 "Estimating multi-country VAR models" by F. Canova and M. Ciccarelli, April 2006.

604 “A dynamic model of settlement” by T. Koeppl, C. Monnet and T. Temzelides, April 2006.

605 “(Un)Predictability and macroeconomic stability” by A. D’Agostino, D. Giannone and P. Surico, April 2006.

606 "Measuring the importance of the uniform nonsynchronization hypothesis" by D. A. Dias, C. Robalo Marques and J. M. C. Santos Silva, April 2006. 
607 "Price setting behaviour in the Netherlands: results of a survey" by M. Hoeberichts and A. Stokman, April 2006.

608 "How does information affect the comovement between interest rates and exchange rates?" by M. Sánchez, April 2006.

609 "The elusive welfare economics of price stability as a monetary policy objective: why New Keynesian central bankers should validate core inflation” by W. H. Buiter, April 2006.

610 "Real-time model uncertainty in the United States: the Fed from 1996-2003" by R. J. Tetlow and B. Ironside, April 2006.

6II "Monetary policy, determinacy, and learnability in the open economy" by J. Bullard and E. Schaling, April 2006.

612 "Optimal fiscal and monetary policy in a medium-scale macroeconomic model" by S. Schmitt-Grohé and M. Uribe, April 2006.

613 "Welfare-based monetary policy rules in an estimated DSGE model of the US economy" by M. Juillard, P. Karam, D. Laxton and P. Pesenti, April 2006. 
